\title{
Aerodynamic Losses in Turbines with and without Film Cooling, as Influenced by Mainstream Turbulence, Surface Roughness, Airfoil Shape, and Mach Number
}

\author{
Phil Ligrani \\ Department of Aerospace and Mechanical Engineering, Parks College of Engineering, Aviation, and Technology, Saint Louis University, \\ 3450 Lindell Boulevard, McDonnell Douglas Hall Room 1033A, St. Louis, MO 63103, USA \\ Correspondence should be addressed to Phil Ligrani, p_ligrani@msn.com
}

Received 22 July 2011; Revised 8 January 2012; Accepted 11 January 2012

Academic Editor: Ting Wang

Copyright (๑) 2012 Phil Ligrani. This is an open access article distributed under the Creative Commons Attribution License, which permits unrestricted use, distribution, and reproduction in any medium, provided the original work is properly cited.

The influences of a variety of different physical phenomena are described as they affect the aerodynamic performance of turbine airfoils in compressible, high-speed flows with either subsonic or transonic Mach number distributions. The presented experimental and numerically predicted results are from a series of investigations which have taken place over the past 32 years. Considered are (i) symmetric airfoils with no film cooling, (ii) symmetric airfoils with film cooling, (iii) cambered vanes with no film cooling, and (iv) cambered vanes with film cooling. When no film cooling is employed on the symmetric airfoils and cambered vanes, experimentally measured and numerically predicted variations of freestream turbulence intensity, surface roughness, exit Mach number, and airfoil camber are considered as they influence local and integrated total pressure losses, deficits of local kinetic energy, Mach number deficits, area-averaged loss coefficients, mass-averaged total pressure loss coefficients, omega loss coefficients, second law loss parameters, and distributions of integrated aerodynamic loss. Similar quantities are measured, and similar parameters are considered when film-cooling is employed on airfoil suction surfaces, along with film cooling density ratio, blowing ratio, Mach number ratio, hole orientation, hole shape, and number of rows of holes.

\section{Introduction}

Numerous investigations consider parameters and phenomena which affect turbine blade and vane aerodynamic losses, such as turbulence intensity, surface roughness, blade row interactions, and blade and vane geometry. Also important are Mach number variations, airfoil camber, and film cooling.

A number of these recent studies focus on aerodynamic losses downstream of subsonic turbine airfoils with no film cooling. Of these investigations, Hoheisel et al. [1], GregorySmith and Cleak [2], and Ames and Plesniak [3] examine the influences of inlet turbulence on losses across turbine cascades. Hoheisel et al. [1] also consider the effects of blade boundary layers, and Ames and Plesniak [3] demonstrate important connections between wake growth and level of freestream turbulence. Moore et al. [4] indicate that more than one third of total losses develop downstream of airfoil trailing edges. The authors attribute total pressure losses to deformation work and dissipation of secondary kinetic energy.

Zhang et al. [5-7], Zhang and Ligrani [8], Xu and Denton [9], Mee et al. [10], Izsak and Chiang [11], Michelassi et al. [12], Joe et al. [13], and Bohn et al. [14] present aerodynamic loss results for transonic turbine airfoils with no film cooling. $\mathrm{Xu}$ and Denton [9] investigate mixing losses from turbine blades with different trailing edge thicknesses, including the influences of blade boundary layers on downstream mixing. According to Mee et al. [10], boundary layers, shock waves, and wakes mixing all contribute to overall losses in relative amounts which depend upon the Mach number. In addition, most of the mixing losses are generated immediately downstream of the trailing edges of blades where gradients in properties across the wake are largest. Izsak and Chiang [11] present experimental data and numerical predictions which account for turbulence, transition, as well as transonic 
expansion fans. Michelassi et al. [12] test turbulence and transition models, which include the effects of separation bubbles, for a cascade flow with shock-boundary layer interactions. Bohn et al. [14] and Joe et al. [13] present aerodynamic loss data measured downstream of airfoils at different Reynolds numbers and exit Mach numbers.

The influence of surface roughness on adjacent flow behavior has been of interest for researchers for almost 100 years. The use of equivalent sandgrain roughness size, $k_{s}$, to characterize and quantify rough surfaces was first proposed and utilized by Nikuradse [15] and Schlichting [16]. This quantity represents the size of sand grains which give the same skin friction coefficients in internal passages as the roughness being evaluated. This measure of roughness size continues to be used widely in empirical correlation equations (which are based on experimental data) to represent rough surface behavior, and for closure models employed in a variety of numerical prediction codes. Sigal and Danberg $[17,18]$ made important advances in accounting for roughness geometry considerations for uniformly shaped roughness elements spread in a uniform pattern over a test surface. For this type of "two-dimensional roughness", the authors provide equations for the dependence of the ratio of equivalent sand grain roughness to mean roughness height, $k_{s} / k$, upon a roughness parameter, $\Lambda_{s}$, which is determined from roughness geometry. Van Rij et al. [19] give a modified version of the Sigal and Danberg correlation for the dependence of $k_{s} / k$ on $\Lambda_{s}$ for randomly placed, non uniform, and three-dimensional roughness with irregular geometry and arrangement. Also described are analytic procedures for determination of roughness height $k$ and $\Lambda_{s}$ from roughness geometry. With this approach, magnitudes of equivalent sandgrain roughness size $k_{s}$ are determined entirely from three-dimensional roughness geometry.

In a paper published in 1975, Bammert and Sandstede [20] describe the influences of different manufacturing tolerances and turbine airfoil surface roughness characteristics on the overall performance of turbines and indicate that losses increase sharply above a certain roughness size. Measurements of the boundary layer development along blades with varying roughness are carried out by the same authors [21] who show that rough surface momentum thickness is up to three times greater than values present in boundary layers on smooth surfaces. Kind et al. [22] investigate the effects of partial roughness coverage of the blade surfaces and conclude that roughness on the suction surface can cause large increases in profile losses. Flat plate surfaces with coneshaped elements are used by Bogard et al. [23] to simulate the roughness present on vane surfaces. According to these investigators, the effects of surface roughness and high freestream turbulence are additive. Abuaf et al. [24] find that tumbling and polishing reduce the average roughness size and improve overall performance when they quantify heat transfer and aerodynamic performance characteristics of turbine airfoils with different surface finish treatments. From experiments conducted using a compressor cascade, Leipold et al. [25] indicate that surface roughness has no effect upon the presence or location of laminar separation, but that roughness causes the turbulent boundary layer to separate at locations further upstream at higher Reynolds numbers. Guo et al. [26] report on the influences of localized pinshaped surface roughness on heat transfer and aerodynamic performance of a fully film-cooled engine aerofoil and indicate that substantial loss increases are present when the pins are located on the pressure side of the airfoil.

Of the investigations which also examine the effects of augmented freestream turbulence levels, Gregory-Smith and Cleak [2] show that the mean flow field is not affected significantly by inlet turbulence intensity levels as high as 5\%. Zhang and Ligrani [27] show that Integrated Aerodynamic Losses (IALs) change significantly as the level of surface roughness changes, where alterations due to different freestream turbulence levels are relatively small. Results presented by these investigators also indicate that thicker rough surface boundary layers are more sensitive to changes of freestream turbulence level than thinner boundary layers that develop over smooth surfaces. Hoffs et al. [28] investigate different surface roughness characteristics at different Reynolds numbers on a turbine airfoil, with turbulence intensity levels as high as 10 percent and show that heat transfer gradually increases and that laminar-to-turbulent transition moves upstream as the Reynolds number and turbulent intensity increase. The effects of strong secondary flows, laminar-to-turbulent transition, and variations near the stagnation line are investigated by Giel et al. [29] using an active blowing grid of square bars as a turbulence generator at the entrance of a transonic cascade. Boyle et al. [30] provide turbine vane aerodynamic data at low Reynolds numbers made at midspan locations downstream of a linear cascade with inlet turbulence intensity levels as high as 10 percent. Nix et al. [31] describe the development of a grid which produces freestream turbulence characteristics which are similar to ones produced by the flow exiting combustors of advanced gas turbine engines.

In a study of aerodynamic losses downstream of turbine airfoil with no film cooling, Jouini et al. [32] present detailed measurements of midspan aerodynamic performance characteristics of a transonic turbine cascade at offdesign conditions. Measurements of blade loading, exit flow angles, and trailing edge base pressures at different Mach numbers show that profile losses at transonic conditions are closely related to base pressure behavior. Radomsky and Thole [33] present measurements of time-averaged velocity components and Reynolds stresses along a turbine stator vane at elevated freestream turbulence levels and present data which show that transition occurs further upstream on the suction side, as the freestream turbulence level increases. Arts [34] describes experimental aerodynamic performance data for a three-dimensional annular transonic nozzle guide vane. Coton et al. [35] investigate the effects of Reynolds number and Mach number on the profile losses of a conventional low-pressure turbine rotor cascade and report that the exit Mach number affects the losses through a modification of the pressure gradient imposed on the boundary layer. Boyle et al. [36] provide aerodynamic data for a linear turbine vane cascade, including surface pressure distributions and aerodynamic losses for different Reynolds numbers, Mach numbers, and levels of inlet turbulence. 
Investigations by Zhang et al. [5] and Zhang and Ligrani [8] employ symmetric airfoils with no camber, and without significant flow turning. Of these, Zhang et al. [5] investigate the effects of surface roughness and turbulence intensity on the aerodynamic losses produced by the suction surface. Their results show that the effects of different inlet turbulence intensity levels are generally relatively small and that diffusion from the wake to surrounding freestream flow results in broader wakes with more uniform aerodynamic wake loss distributions. The data of Zhang and Ligrani [8] show that magnitudes of Integrated Aerodynamic Losses change by much larger amounts as either the freestream Mach number or turbulence intensity are altered, when the airfoil is roughened (compared to smooth airfoil results). Other recent investigations are described by Zhang et al. $[37,38]$ and by Zhang and Ligrani $[39,40]$.

In recent years, designers have devoted increased attention to the aerodynamic penalties associated with film cooling of turbine airfoils in gas turbine engines. This is because of increased awareness of the drops in efficiency associated with such penalties, and because the improvements in thermal protection provided by newest film hole configurations may be offset by the total pressure aerodynamic losses which accumulate downstream of the airfoils. Thus, it is paramount that such aerodynamic losses be quantified, especially for transonic turbine airfoils, where total pressure losses often develop from shock waves, boundary layers, and wake mixing. Film cooling is employed to maintain gas turbine hot-section components with acceptable temperatures and temperature gradients in order to increase engine performance by allowing operation at higher gas inlet temperature with increased component life. Acceptable temperature levels are a vital characteristic because they lead to less susceptibility to high-temperature oxidation, creep, corrosion, and thermomechanical fatigue.

Of recent investigations in this area, Denton [41] indicates that total pressure losses are connected to entropy creation. Consequently, mixing across gradients in the flow can result in increased losses even without the action of frictional forces. Additional entropy increases and losses of stagnation pressure also often result due to separation bubbles which act to thicken boundary layers. Because boundary layer losses depend upon the cube of the ratio of the blade surface velocity to the upstream reference velocity integrated over the surface of an airfoil, losses originating in the suction surface boundary layer are dominant [41].

Other investigators who consider the influences of film cooling on aerodynamic losses from turbine blades and vanes include Jackson et al. [54] and Ito et al. [42]. Of these investigations, Ito et al. [42] indicate that total pressure losses in incompressible flow can increase or decrease due to film injection from a single row of holes placed either on the suction surface or the pressure surface. Haller and Camus [43] present losses due to film cooling for five separate cooling hole locations on a transonic airfoil, using carbon dioxide to simulate an operating engine density ratio. Their results show that ejection downstream of the passage throat does not necessarily give greater losses compared to situations with injection upstream of the throat. Kollen and Koschel [44] also utilize carbon dioxide for the film on a transonic airfoil. From this study, losses increase with blowing ratio for film cooling from the leading edge and decrease with blowing ratio when the film cooling is located on the suction surface, except when the blowing ratio is very small.

In an investigation performed by Day et al. [45] which considers the effects of film cooling, a cascade is employed which operates at conditions similar to those which exist in gas turbine engines. The authors show that utilizing cylindrical holes increases aerodynamic losses by 6.7 percent, and that utilizing fan-shaped holes increases losses to 15 percent compared to a no-injection condition. They also show that film cooling at the leading edge, and early pressure surface region can actually increase aerodynamic efficiency, most likely because of shock/boundary layer interactions. Hong et al. [46] examine the effects of film cooling from a single row of holes located either on the suction surface, pressure surface, or leading edge. Results indicate that the suction surface film cooling has the biggest influence on aerodynamic losses, and that pressure surface film cooling has the smallest influence on losses.

Mee et al. [10], Michelassi et al. [12], Bohn et al. [14], Kapteijn et al. [47], Vlasic et al. [48], Sieverding et al. [49], and Tanuma et al. [50] investigate losses downstream of transonic airfoils with trailing edge ejection. Mee et al. [10], Day et al. [45], and Osnaghi et al. [51] all indicate that density ratio influences are well correlated using the momentum flux ratio. According to Day et al. [45], film cooling causes thickening of airfoil wakes, as well as changes to the flow field near the hub in an investigation of aerodynamic losses from a transonic airfoil with multiple rows of film cooling holes on the leading edge and suction surface. Kubo et al. [52] compare numerical predictions with total pressure losses measured downstream of a low-speed cascade containing a vane with film-cooling holes located on the leading edge, suction surface, pressure surface, and trailing edge. As the mass flow rate ratio varies, the largest loss increases relative to the flow with no film cooling are due to injection from holes located near the passage throat on the suction surface and from holes on the leading edge. In another experimental and numerical investigation which employs transonic airfoils, Urban et al. [53] also show that losses are greatly increased by film cooling from the suction surface, whereas pressure side and trailing edge ejection produces only small changes to aerodynamic loss magnitudes. Density ratio variations are shown to have insignificant influences on loss magnitudes by these investigators.

Within the present investigations, losses from friction and expansions/compressions are considered as they result from flow separations, viscous effects within boundary layers, shear augmentation in wakes, mixing processes within wakes and boundary layers, shock waves, and the generation, growth, and mixing of vortices. According to Denton [41], for a complete turbomachinery stage, these phenomena can also be categorized as "profile loss," "endwall loss," and "leakage loss," where "profile loss" is due to boundary layer growth and separation from the trailing edge. Of particular interest here are the effects of Mach number, 
mainstream turbulence intensity, surface roughness, film cooling, and airfoil shape on such phenomena, as quantified using Integrated Aerodynamic Loss [5, 8, 27, 37-39, 54, 55].

\section{Aerodynamic Loss Determination}

2.1. Primary Loss Coefficient and Thermodynamic Loss Coefficient. Nondimensional loss coefficients are key performance metrics in the analysis of turbomachines. According to Raffel and Kost [56], Kost and Holmes [57], and others [10, 58], a primary loss coefficient, which is also referred to as an enthalpy loss coefficient [41], is given by

$$
\xi=1-\left[\frac{\left(h_{o e}-h_{s e}\right)}{\left(h_{o i}-h_{s e, \text { ideal }}\right)}\right]
$$

which is also equivalent to the following:

$$
\xi=1-\left[\frac{W_{e}^{2}}{W_{e, \text { ideal }}^{2}}\right]=1-\left[\frac{\left(1-\left(P_{s e} / P_{o e}\right)^{(k-1) / k}\right)}{\left(1-\left(P_{s e} / P_{o i}\right)^{(k-1) / k}\right)}\right],
$$

where $W$ is the local relative velocity. A local thermodynamic loss coefficient is then employed to account for the different energy input of coolant flow relative to the mainstream flow [56-58]

$$
\xi_{\text {th }}=1-\left[\frac{\left(1+\left(\dot{m}_{c} / \dot{m}_{\infty}\right)\right) W_{e}^{2}}{\left(W_{e, \text { ideal }}^{2}+\left(\dot{m}_{c} / \dot{m}_{\infty}\right) W_{c, \text { ideal }}^{2}\right)}\right] .
$$

Equation (3) can also be expressed using an equation given by

$$
\begin{aligned}
\xi_{\text {th }}=1-[( & \left.+\left(\dot{m}_{c} / \dot{m}_{\infty}\right)\right)\left(1-\left(P_{s e} / P_{o e}\right)^{(k-1) / k}\right) h_{o e} / \\
& \left(\left(1-\left(P_{s e} / P_{o i}\right)^{(k-1) / k}\right) h_{o i}\right. \\
& \left.\left.+\left(\dot{m}_{c} / \dot{m}_{\infty}\right)\left(1-\left(P_{s e} / P_{o c}\right)^{(k-1) / k}\right) h_{o c}\right)\right] .
\end{aligned}
$$

The challenge in utilizing (4) to represent a film-cooled environment (especially when the flows are compressible) lies in the difficulty of estimating appropriate values of either temperature or enthalpy which are correctly representative of energy content. For example, ambiguity always exists regarding choices of idealized values of $h_{o i}$ and $h_{o c}$, to appropriately represent isentropic kinetic energy values for the mainstream and coolant, respectively. In addition, magnitudes of $h_{o e}$ within (4) must be representative of overall, mixed values.

2.2. Entropy Rise Coefficient. According to Denton [41], an entropy rise coefficient can also be utilized to characterize turbomachinery stage losses. Such a coefficient is defined using

$$
Y_{S}=\frac{\left[T_{2}\left(s_{e}-s_{i}\right)\right]}{\left[W_{e}^{2} / 2.0\right]}
$$

For small losses in incompressible flow, this is then equivalent to

$$
Y_{P}=\frac{\left(P_{o i}-P_{o e}\right)}{\left(P_{o i}-P_{s e}\right)}
$$

which is, thus, also a second-law loss coefficient. Such coefficients are useful because they allow appropriate comparisons to be made between different airfoils, with different filmcooling arrangements, at different flow velocities.

2.3. Omega Aerodynamic Loss Coefficients. Within investigations which generally involve low-speed turbine cascades $[3,59-63]$, a total pressure loss coefficient $\Omega=\left(P_{o i}-\right.$ $\left.P_{o e}\right) /\left(P_{o i}-P_{s e}\right)$ is employed, which is equivalent to the $Y_{P}$ quantity given by (6). Within this definition, each term is generally determined locally at a particular spatial location. Here, the stagnation pressure loss is normalized by idealized dynamic pressure, which is equivalent to the sum of the stagnation pressure loss and the local exit dynamic pressure.

In the investigations of Ames et al. [59] and Johnson et al. [61], cross-passage mass-averaged and full exit massaveraged magnitudes of aerodynamic loss (determined by integrating distributions of loss coefficient $\Omega$ ) are also determined. With mass averaging, the $\left(P_{o i}-P_{o e}\right)$ quantity within the total loss coefficient $\Omega$ is multiplied by local mass flow rate. The result is normalized by overall mass flow rate multiplied by $\left(P_{o i}-P_{s e}\right)$. This gives the massweighted stagnation pressure loss, relative to overall ideal dynamic pressure for the equivalent of one blade passage. Ames et al. [59], Johnson et al. [61], and Fiala et al. [63] also consider local and cross-passage mass-averaged magnitudes of turning angle, which is defined as the outlet flow angle measured relative to the inlet axial direction.

An example of smooth airfoil $\left(P_{o i}-P_{o e}\right) /\left(P_{o i}-P_{s e}\right)$ total pressure loss coefficient profiles for different turbulence intensity levels is presented in Figure 4. Here data from Ames and Plesniak [3] are included, along with data from Zhang et al. [5] for smooth, symmetric airfoils. Additional discussion of the trends and physical significance of the results presented in Figure 4 are given later in the present paper.

2.4. Area-Averaged Loss Coefficients. Boyle and Senyitko [64] and Boyle et al. [30] employ an area averaged loss coefficient, $Y_{A}$, in their analysis, which is defined using an equation of the form

$$
Y_{A}=\frac{p_{o i}-p_{o e, A}}{p_{o i}-p_{s e, A}}
$$

The form of (7) is similar to the form of (6), except, here, $p_{o e, A}$ and $p_{s e, A}$ are area averaged exit total pressure and static pressure, respectively. These are determined using equations, respectively, given by

$$
\begin{aligned}
& p_{o e, A}=\int_{-p / 2}^{p / 2} p_{o e}\left(\frac{d y}{p}\right), \\
& p_{s e, A}=\int_{-p / 2}^{p / 2} p_{s e}\left(\frac{d y}{p}\right) .
\end{aligned}
$$

Examples of area-averaged loss coefficient $Y_{A}$ data are presented in Figure 20. Here, $Y_{A}$ data from Boyle and Senyitko [64] are given which are based on measurements made 0.35 of an axial chord length downstream of their vane trailing edge. Vanes are employed with $5.18 \mathrm{~cm}$ axial 
chord length and $75^{\circ}$ flow turning angle. The prediction results from Boyle et al. [30] represent data from vanes with $4.445 \mathrm{~cm}$ axial chord length and approximately $80^{\circ}$ flow turning angle in their numerical prediction. Figure 20 also includes results from Zhang et al. [37] measured downstream of a smooth cambered vane at two different exit Mach numbers for a location $0.25 c x$ downstream of the vane. The physical significance of the results and data trends which are apparent in Figure 20 are discussed in greater detail later in the present paper.

2.5. Mass-Averaged Loss Coefficients. Kind et al. [22] employ a mass-averaged loss coefficient, $Y_{p}$ in their turbine cascade investigation, which is defined using

$$
Y_{p^{\prime}}=\frac{P_{o i}-P_{o e, m}}{q_{e, m}} .
$$

Here, $P_{o e, m}$ and $q_{e, m}$ are mass-averaged exit total pressure and mass-averaged dynamic pressure, respectively. These two parameters are defined with equations that are given by

$$
\begin{gathered}
P_{o e, m}=\frac{\int_{-p / 2}^{p / 2} \rho u P_{o e} d y}{\rho_{\infty} u_{\infty} p}, \\
q_{e, m}=\frac{\int_{-p / 2}^{p / 2} \rho u q_{e} d y}{\rho_{\infty} u_{\infty} p},
\end{gathered}
$$

respectively. $Y_{p^{\prime}}$ data from Kind et al. [22] are presented and compared with some data from Zhang et al. [38] in Figure 22. The Kind et al. data are measured 0.4 of an axial chord length downstream of their airfoil. Here, $Y_{p^{\prime}}$ loss coefficient data are given as they vary with normalized mean roughness height $k / c x$ since sandgrain roughness height, $k_{s}$, is not available from Kind et al. [22]. Figure 22 is also discussed in greater detail later in the present paper.

The approach utilized by Kind et al. is similar to methods employed by Friedrichs et al. [65], where, instead of massaveraging, the $P_{o e}$ and $P_{s e}$ quantities are determined as massaveraged, "mixed" quantities within total loss coefficients (6). These investigators also employ three different approaches for determination of the reference inlet stagnation pressure, each with a different means for inclusion of contributions from the film coolant supply.

2.6. Local Total Pressure Loss Coefficient and Integrated Aerodynamic Loss. $C_{p}$ is the normalized inlet total pressure minus exit total pressure $[5,8,27,37-39,54,55]$, which is expressed using an equation of the form

$$
C_{p}=\frac{P_{o i}-P_{o e}}{P_{o i}}=1-\left(\frac{P_{o e}}{P_{o i}}\right) .
$$

With this approach, the local stagnation pressure loss is normalized by a quantity which does not vary with cascade exit location.

Zhang et al. [5, 37, 38], Jackson et al. [54], Chappell et al. [55], and Zhang and Ligrani [8, 27, 39, 40] employ integrated aerodynamic loss IAL to quantify aerodynamic losses in turbine components. Dimensional magnitudes of Integrated Aerodynamic Loss, IAL, are determined by integrating profiles of $\left(P_{o i}-P_{o e}\right)$ with respect to $y$ in the transverse flow direction across the wake for one single vane spacing, from $-p / 2$ to $p / 2$ [54]. In equation form, IAL is thus given by

$$
\mathrm{IAL}=\int_{-p / 2}^{p / 2}\left(P_{o i}-P_{o e}\right) d y .
$$

Here, IAL magnitudes are determined from measured distributions of the local total pressure loss coefficient, $C_{p}$, which are measured downstream of the airfoil. Consequently, IAL magnitudes represent mixing losses which have accumulated through the wake and airfoil boundary layers [54].

These forms for IAL and $C_{p}$ are employed because they are directly related to local entropy change and to local entropy creation. When normalized using either $P_{o i} p$ or $\left(P_{o i}-P_{s e}\right) p$, IAL magnitudes can then be compared to data sets obtained at different velocities and with different airfoil configurations. In addition, for the compressible transonic and subsonic results which are presented later in the paper, IAL-based correlations which account for film cooling are simpler, more consistent, and more physically meaningful than when other types of loss coefficients are employed. According to Osnaghi et al. [51] and Drost and Bölcs [58], direct connections exist between the wake coolant distribution and total pressure losses (provided analogous behavior between coolant mass diffusion and momentum diffusion is assumed).

Examples of profiles of local total pressure loss coefficient, $C_{p}$, are given in Figure 5(a). These particular results illustrate the effects of surface roughness for an inlet turbulence intensity level of 0.9 percent [8]. Data are given for $k_{s} / c x$ values of $0,0.00069$, and 0.00164 , which correspond to the smooth, small-sized roughness, and large-sized roughness, respectively. The inlet total pressure is kept constant at $195 \mathrm{kPa}$ when different airfoils are employed. The results in this set of figures are given for an exit freestream Mach number 0.9 , and for a low value of inlet turbulence intensity, because variations due to roughness are often generally more apparent than for higher inlet turbulence intensity levels. Figure 5(a) shows that total pressure losses increase at each $y / c x$ location as $k_{s} / c x$ increases. This is apparent at peak value locations and is accompanied by increases in the width of the profiles as roughness size becomes larger. These trends, including their significance are discussed in greater detail later in the present paper.

Examples of IAL data are given in Figure 6, which are normalized using the airfoil passage effective pitch $p$ and test section inlet stagnation pressure $P_{o i}$. These particular data are given as they depend upon $k_{s} / c x$ for different $T u$ values, for the airfoils with the smooth surfaces $\left(k_{s} / c x=0\right)$, small-sized roughness $\left(k_{s} / c x=0.00069\right)$, and large-sized roughness $\left(k_{s} / c x=0.00164\right)$. The results which are presented in Figure 6 are also discussed in greater detail later in the present paper.

2.7. Second Law Losses. Local and global aerodynamic losses can also be further quantified using additional second law analyses. For adiabatic and isothermal flow, the entropy 
change from inlet to outlet of the present cascade arrangements, shown in Figures 1 and 12, is given by

$$
\Delta s=s_{e}-s_{i}=-R \ln \left(\frac{P_{o e}}{P_{o i}}\right)=-R \ln \left(1-C_{p}\right) .
$$

Here, $C_{p}$ is the local total pressure loss coefficient, given by (12). According to Denton [41], pressures, temperatures, and densities which are used to determine entropy changes can be either all static values or all stagnation values because, by definition, the change from static to stagnation condition is isentropic. Equation (14) then omits any changes due to stagnation temperature variation since this quantity is constant through adiabatic blade row arrangements.

From a general perspective, irreversibilities and local entropy creation from second law losses occur from three overall sources, namely, heat transfer, friction, and expansions/compressions [66]. Only the latter two effects are considered within the present investigation as they result from flow separations, viscous effects within boundary layers, shear augmentation in wakes, mixing processes within wakes and boundary layers, shock waves, and film cooling. As mentioned earlier, these phenomena can also be categorized as "profile loss," "endwall loss," and "leakage loss," where "profile loss" is due to boundary layer growth and separation from the trailing edge [37, 41]. These effects generate entropy, and anything, that generates entropy, always destroys exergy. To estimate the amount of energy that can be extracted as useful work, or the useful work potential of a given amount of energy at some specified state, exergy (which is also called the availability or available energy) is employed [66]. From (12) and (14), the local entropy creation is then represented by

$$
s_{\text {gen }}=T_{0} \Delta s,
$$

where $T_{0}$ is the laboratory ambient temperature $\left(T_{0}=\right.$ $300 \mathrm{~K})$. The exergy destroyed is then proportional to the entropy created. The mass-averaged overall exergy destruction is subsequently expressed using

$$
x_{\text {dest }, o}=\frac{1}{\rho_{\infty} u_{\infty} p} \int_{-p / 2}^{+p / 2} \rho u s_{\text {gen }} d y .
$$

This then represents the overall lost work potential. Multiplying $x_{\text {dest }, o}$ by the appropriate mass flow rate then gives the overall rate of exergy destruction.

Examples of mass-averaged magnitudes of overall exergy destruction are given in Figure 26 for a cambered vane and a symmetric airfoil, as they vary with surface roughness. These data are given for different measurement locations downstream of different airfoils with different exit Mach numbers, for freestream turbulence intensity values from 0.9 to 1.5 percent. Dramatic increases of $x_{\text {dest }, o}$ are generally apparent as either $k_{s} / c$ or as $M_{e x}$ increases. Additional discussions of these results are also given later within the present paper.

\section{Present Investigations}

When symmetric airfoils and cambered vanes are employed, both with and without film cooling, effects of mainstream turbulence intensity, surface roughness, exit Mach number, and airfoil camber are considered as they influence local and integrated parameters which quantify aerodynamic losses. Of particular interest is the effect of such parameters on $C_{p}$ total pressure loss coefficients, $\Omega$ total pressure loss coefficients, and IAL or Integrated Aerodynamic Loss. The associated results are presented in five sections: (i) symmetric airfoils with no film cooling, (ii) symmetric airfoils with film cooling, (iii) cambered vanes with no film cooling, (iv) cambered vanes with film cooling, and (v) second law analyses of turbine aerodynamic losses with and without film cooling.

\section{Symmetric Airfoils with No Film Cooling}

Investigations of symmetric turbine airfoils (with no film cooling) consider the effects of surface roughness, freestream Mach number, and mainstream turbulence intensity on aerodynamic losses downstream of the airfoils in compressible, high-speed flow. Combined and coupled effects of these different phenomena are considered $[5,6,8]$. The presence and development of shock waves for the transonic case are also discussed, along with shock wave changes that occur as the level of surface roughness changes. Three symmetric airfoils are employed, with different rough surfaces which are characterized using equivalent sandgrain roughness size. Magnitudes of equivalent sandgrain roughness size for each surface are determined using three-dimensional optical profilometry data, and procedures described by Van Rij et al. [19]. Exit freestream Mach numbers measured one chord length downstream of the airfoil are 0.6, 0.8, and 0.9. The magnitudes of longitudinal turbulence intensity used at the inlet of the test section are 0.9 percent, 5.5 percent, and 16.2 percent, where the latter values are produced using a mesh grid and cross-bars, respectively. Additional details on experimental apparatus and procedure details, including the Transonic Wind Tunnel, are provided by Zhang et al. [5-7], Furukawa and Ligrani [67], and Zhang and Ligrani [8], including discussion of techniques to determine rough-surface skin friction coefficients from wake profile measurements [7].

4.1. Test Section and Test Vane. A schematic diagram of the nonturning airfoil cascade test section is shown in Figure 1. The inlet of the test section is $12.70 \mathrm{~cm}$ by $12.70 \mathrm{~cm}$. The two side walls are flat, whereas the top and bottom walls are contoured to form a converging-diverging shape which produces the desired Mach number distribution along the symmetric test airfoil. Because significant flow turning is not included, the camber curvature, present in many cascades with multiple airfoils, is not present. The airfoil chord length is $7.62 \mathrm{~cm}$, the leading edge diameter is $0.3 \mathrm{~cm}$, the effective pitch is $5.08 \mathrm{~cm}$, the span is $12.7 \mathrm{~cm}$, and the trailing edge of the symmetric airfoil is a $1.14-\mathrm{mm}$-radius round semicircle.

The present test section is useful and advantageous over cascade arrangements with multiple airfoils and significant flow turning because (i) the test section produces Mach numbers, pressure variations, Reynolds numbers, passage mass flow rates, and physical dimensions which match values 


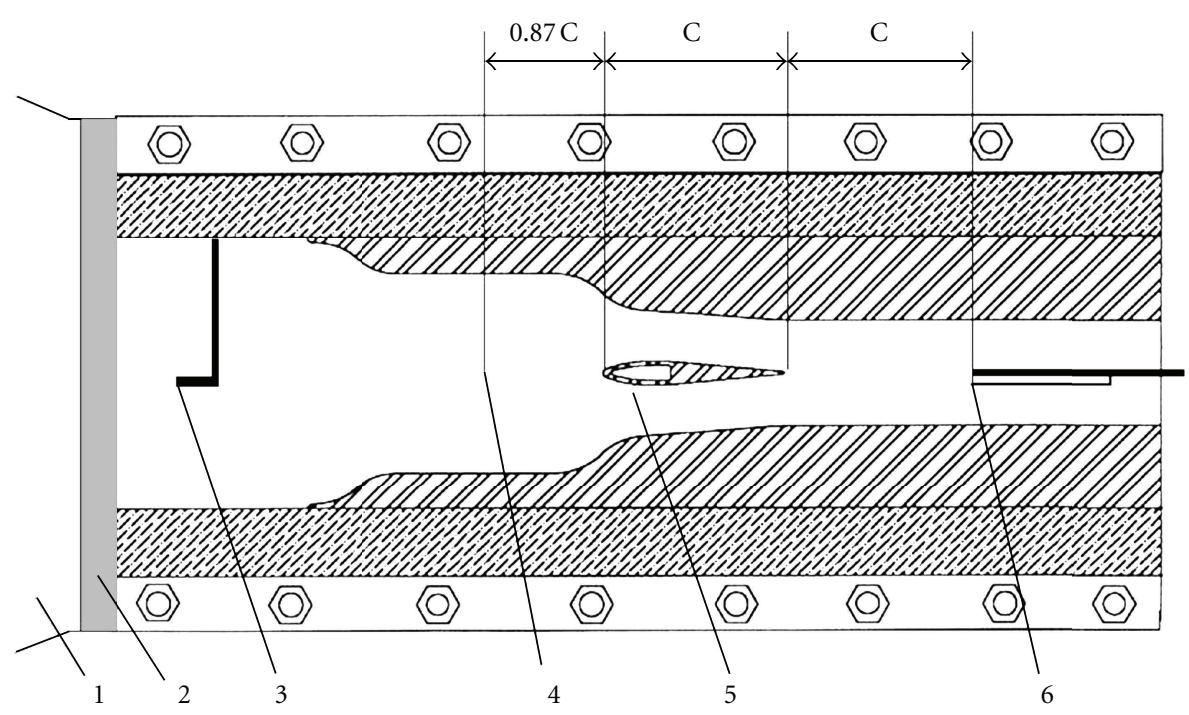

(1) Nozzle

(2) Grid/bar turbulence generator

(3) Inlet pressure probe and thermocouple

(4) Measurement location for inlet turbulence intensity and flow uniformity

(5) Test airfoil

(6) Exit pressure probe and thermocouple

Figure 1: Schematic diagram of the test section employed for the symmetric airfoil investigations [5-8].

along airfoils in operating engines, (ii) the airfoil provides the same suction surface boundary layer development (in the same pressure gradient without flow turning) as exists in operating engines, (iii) aerodynamic loss data are obtained on airfoil surfaces without the complicating influences of vortices present along airfoil pressure surfaces, and (iv) only one airfoil is needed to obtain representative flow characteristics. Thus, the present experiment is designed to isolate the effects of Mach numbers, surface roughness, and turbulence intensity on wake aerodynamic losses, while matching Reynolds numbers, Mach numbers, pressure gradients, passage flow rates, boundary layer development, and physical dimensions of airfoils in operating engines.

\subsection{Test Section Flow Characteristics and Mach Number} Distributions. Three different arrangements are used at the inlet of the test section to produce three different levels of mainstream turbulence intensity: (i) no grid or bars, (ii) fine mesh grid, and (iii) crossbars. With no turbulence grid employed at the test section inlet, the magnitude of the longitudinal turbulence intensity is 0.9 percent. With the fine mesh turbulence generating grid, the intensity and length scale are 5.5 percent, and $15.24 \mathrm{~mm}$, respectively. With the cross bar turbulence generating grid, the intensity and length scale are 16.2 percent, and $19.70 \mathrm{~mm}$, respectively. These values are measured at a location which is 87 percent of one chord length upstream of the airfoil leading edge. For each of the three different values of inlet total pressure, magnitudes of turbulence intensity and turbulence length scale are about the same because they are mostly a result of the specific turbulence generator employed $[5,8]$.

Mach number distributions, measured along the airfoil, are shown in Figure 2 and are similar to values present on turbine airfoil suction surfaces. These values are based upon measurements of total pressure at the test section inlet and static pressures measured along the midspan line of a smooth airfoil, which is employed especially for this task. The eight measured values shown in Figure 2 are based upon measurements made along the top of surface of the smooth airfoil at freestream $T u=0.9 \%$. These values are in excellent agreement with Mach numbers measured at three different locations on the bottom surface of the airfoil.

During each test, the total pressure at the inlet of the test section, $P_{o i}$, is kept constant at one of the different values, at either $114 \mathrm{kPa}, 140 \mathrm{kPa}$, or $195 \mathrm{kPa}$. Corresponding exit freestream Mach numbers, measured one chord length downstream of the airfoil trailing edge, are $0.6,0.8$, and 0.9, respectively, and chord Reynolds numbers (based on exit flow conditions) are $1.02 \times 10^{6}, 1.38 \times 10^{6}$, and $1.96 \times 10^{6}$, respectively.

With the highest inlet total pressure and the smooth airfoil, the flow in the passage is transonic and the trailing edge Mach number is 1.1. With this arrangement, a finite region of supersonic flow exists near the downstream portion 


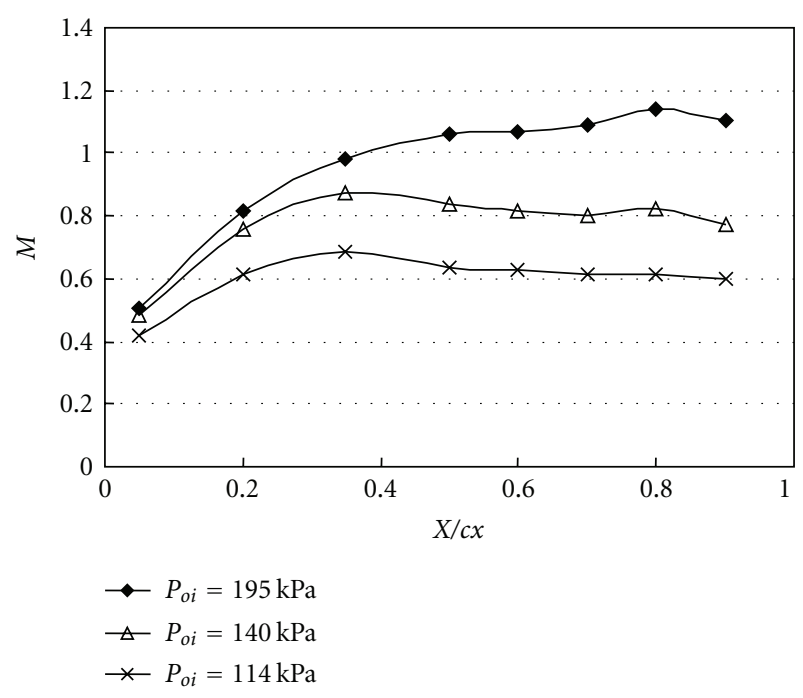

Figure 2: Airfoil Mach number distributions employed for the symmetric airfoil investigations $[5,8]$.

of the airfoil, and a pair of oblique shock waves are present at the airfoil trailing edge. Numerical predictions of the Mach number distribution through the test section with this flow arrangement are presented in Figure 3 from Jackson et al. [54]. Here, the angle produced by the strong oblique shock waves at the airfoil trailing edge is about $73^{\circ}$ (measured from the airfoil symmetry plane). This value and measured total pressures downstream of the oblique shock waves are in good agreement with theoretical values for a $5^{\circ}$ flow deflection angle from Anderson [68]. The positions and shapes of the oblique shock waves from Schlieren images, also from Jackson et al. [54], show good qualitative agreement with the Mach number distribution which is given in Figure 3.

4.3. Rough Surface Characterization. The magnitudes of equivalent sandgrain roughness are determined for all three surfaces tested (smooth, small-sized roughness and largesized roughness) using procedures which are described by Van Rij et al. [19], Zhang et al. [5], and Zhang and Ligrani [8].

The first step in this approach is a detailed determination of surface contour coordinates using a Wyko high-resolution optical Surface Profilometer. These optical profilometry data show that the rough surface from the pressure side of a turbine blade with particulate deposition from a utility power engine has irregularity, nonuniformity, and three dimensionality, including irregular arrangement. Equivalent sand grain roughness size of this real turbine blade surface is about $62.3 \mu \mathrm{m}$, which is close to the size of test surface of small-sized roughness elements $(52.59 \mu \mathrm{m})$, as indicated in Table 1. This table also shows that magnitudes of other surface roughness statistics from the utility power engine turbine blade are similar to test surfaces employed with small-sized and large-sized roughness elements.

The next step in the procedure to determine equivalent sandgrain roughness magnitudes is numerical determination

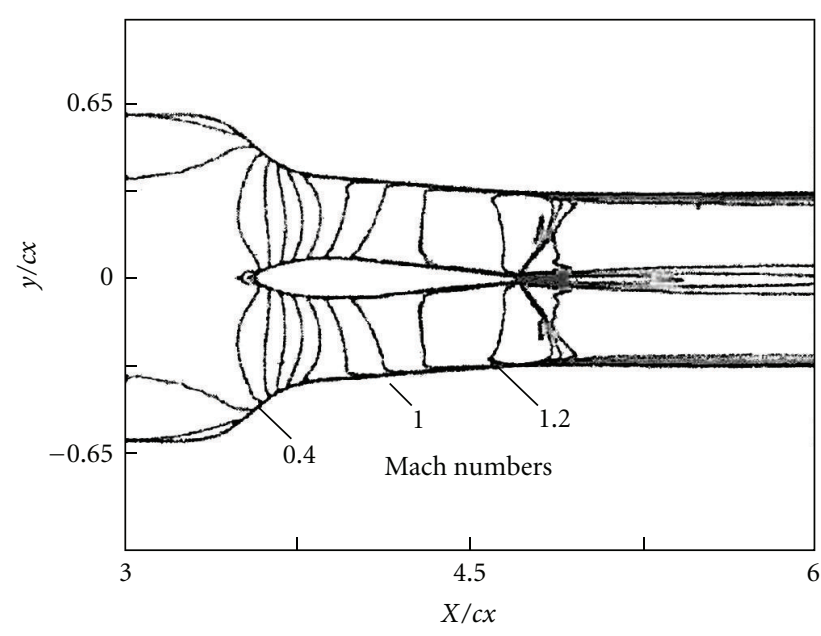

FIGURE 3: Numerically predicted Mach number distribution through the test section for the symmetric airfoil investigations [54].

of a modified version of the Sigal and Danberg roughness parameter $\Lambda_{s}$ [17-19]. The procedures to accomplish this are described by Van Rij et al. [19] and involve determination of the rough surface flat reference area, the total roughness frontal area, and the total roughness windward wetted surface area. With $\Lambda_{s}$ known, the ratio of equivalent sandgrain roughness size to mean roughness height, $k_{s} / k$, is determined using a correlation for three-dimensional, irregular roughness with irregular geometry and arrangement, which is given by Van Rij et al. [19]. The mean roughness height $k$ is then also estimated by taking the distance between the maximum point of the ensemble average of all of the roughness peaks in any roughness sample, and a base height. Determination of this base location is based on analytic procedures which are also given by Van Rij et al. [19].

With this approach, magnitudes of equivalent sand grain roughness size for the three-dimensional, irregular roughness of the present study are determined. Values are given in Table 1 (which are based on an average of 8 profilometry scans), along with magnitudes of $\Lambda_{s}$ and $k_{s} / k$.

4.4. Comparisons between Investigations. Figure 4 compares smooth airfoil $\Omega$ or $\left(P_{o i}-P_{o e}\right) /\left(P_{o i}-P_{s e}\right)$ total pressure loss coefficient profiles for different turbulence intensity levels to ones from Ames and Plesniak [3]. For both studies, peak coefficients decrease, with broader distributions over larger ranges of $y / c x$ values, as $T u$ increases. Similar qualitative trends are thus evident, even though quantitative values are different. Quantitative differences are due to a number of factors, including different airfoil configurations (curved, straight) and different flow conditions (low-speed, highsubsonic-compressible). In contrast to the present study, Ames and Plesniak [3] also report substantial losses in the freestream, as mentioned. In their low-speed cascade experiments, Ames and Plesniak [3] also observe wake broadening with increasing mainstream turbulence intensity and associate these with smaller peak velocity deficits. As 
TABLE 1: Characteristics of rough surfaces employed for the symmetric airfoil investigations [8].

\begin{tabular}{|c|c|c|c|c|c|}
\hline Surface & $\Lambda_{s}$ & $k_{s} / k$ & $k(\mu \mathrm{m})$ & $k_{s}(\mu \mathrm{m})$ & $k_{s} / c$ \\
\hline Large-sized roughness & 15.45 & 1.96 & 64.03 & 125.2 & 0.0016 \\
\hline Small-sized roughness & 20.10 & 1.89 & 27.92 & 52.59 & 0.0007 \\
\hline smooth & - & 0.003 & 3.50 & 0.0094 & 0 \\
\hline Turbine blade from a utility power engine & 43.460 & 1.640 & 40.820 & 62.300 & 0.00080 \\
\hline
\end{tabular}

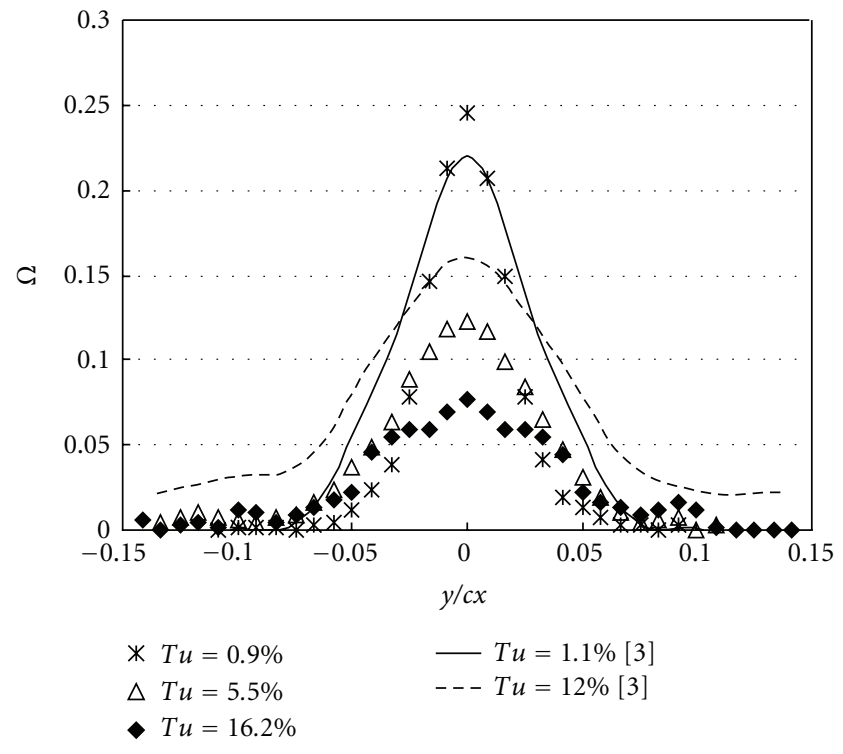

Figure 4: Comparisons of total pressure loss coefficients for symmetric airfoils [5], with ones from Ames and Plesniak [3] for smooth airfoils $\left(k_{s} / c x=0\right)$.

mentioned, increased diffusion from the wake to surrounding freestream flow plays an important role in producing such trends. Note that aerodynamic loss contributions in the freestream are also substantial in the results obtained by Ames and Plesniak. This is a partial result of the streamline curvature which is present in their experiments. As a result, elevated freestream turbulence intensity levels substantially increase overall loss magnitudes in their experiments. In the present study, the total pressure at inlet of test section is almost the same as the total pressure in the freestream at the outlet. This means that losses in the freestream are negligible in the present investigation. Boyle et al. [36] also find negligible freestream losses in their high-speed cascade experiments, but they present significantly different trends from Ames and Plesniak [3], as well as the present study, since peak total pressure loss magnitudes increase as the level of mainstream turbulence increases.

4.5. Local Aerodynamic Performance. Figures 5(a)-5(d) show example results to illustrate the effects of surface roughness on normalized local total pressure losses $C_{p}$, normalized local Mach numbers $M_{e} / M_{e, \infty}$, normalized local kinetic energy KE profiles, and profiles of the $\Omega$ total pressure loss coefficients for an inlet turbulence intensity level of 0.9 percent [8]. Data are given for $k_{s} / c x$ values of $0,0.00069$, and 0.00164 , which correspond to the smooth, small-sized roughness, and largesized roughness, respectively. The inlet total pressure is kept constant at $195 \mathrm{kPa}$ when different airfoils are employed. The results in this set of figures are given for an exit freestream Mach number 0.9, and for a low value of inlet turbulence intensity, because variations due to roughness are often generally more apparent than for higher inlet turbulence intensity levels. Figure 5 shows that total pressure losses, Mach number deficits, deficits of kinetic energy, and $\Omega$ total pressure losses all increase at each $y / c x$ location as $k_{s} / c x$ increases. This is apparent at peak value locations and is accompanied by increases in the width of the profiles as roughness size becomes larger. This is largely due to increased thickening of the boundary layers along the airfoil surfaces as $k_{s} / c x$ increases, which is accompanied by higher magnitudes of Reynolds stress tensor components, higher magnitudes of local turbulent transport, and higher surface skin friction coefficients. The broader wakes with increased roughness size in Figure 5 are then the result of (i) augmentations of mixing and turbulent transport in the boundary layers which develop along the roughened airfoils, (ii) thicker boundary layers at the airfoil trailing edges of the roughened airfoils, and (iii) increased turbulent diffusion in the transverse direction within the wake as it advects downstream [8]. Note that the $\Omega$ profiles in Figure 5(d) are qualitatively similar to the $C_{p}$ profiles in Figure 5(a). This is because the static pressure through the wake $P_{s e}$ varies by only a small amount, with a maximum decrease relative to the freestream value $P_{\text {ses }}$ of only about 8.5 percent.

For the present airfoil shape and configuration, numerical predictions by Zhang and Ligrani [39] show that flow separation regions (as well as associated form drag contributions) are about the same for all three airfoils, regardless of their $k_{s} / c x$ value (of either $0,0.00069$, or $0.00164)$. Numerical results also show that boundary layers are almost entirely turbulent along the entire length of all three tested airfoils. From these numerical predictions, values of $k_{s}^{+}$just before the airfoil trailing edge for $M_{e, \infty}=0.6$, normalized by friction velocity and kinematic viscosity, are approximately 24.8 and 60.9 for the small-sized roughness and large-sized roughness, respectively [39].

Other changes due to surface roughness are apparent in the $C_{p, \infty}$ values in Figure 5(a) for $M_{e, \infty}=0.9$, which are measured in the flow outside of the wake. With the smooth airfoil, the $C_{p, \infty}$ values in the freestream are approximately 0.003-0.007 which correspond to $\left(P_{o i}-P_{o e, \infty}\right)$ values of $0.4-1.4 \mathrm{kPa}$. The resulting difference in stagnation pressure between the inlet and exit of the test section is due to a pair of oblique shock waves present at the trailing edge of the airfoil 


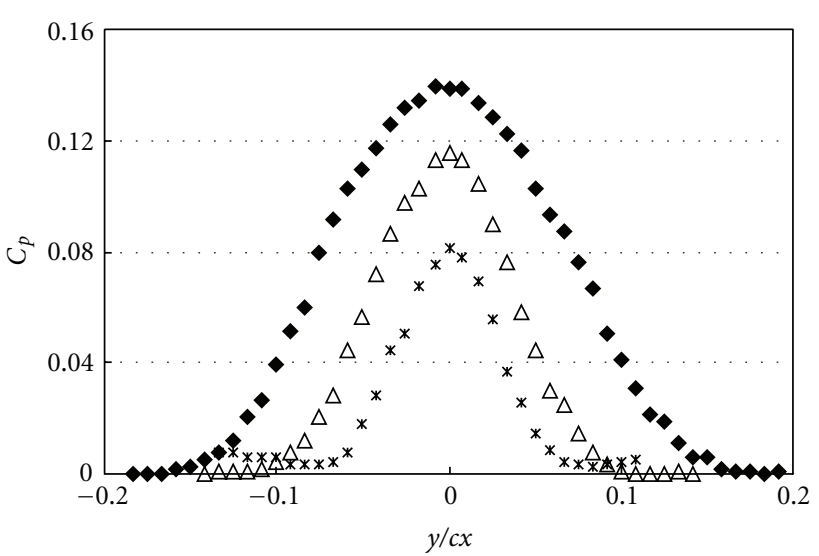

(a)

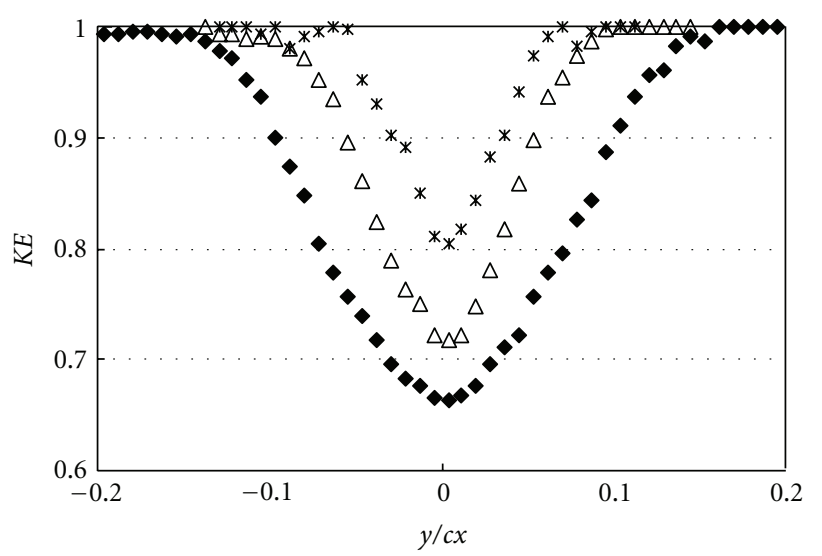

* $k_{s} / c x=0$

$\Delta k_{s} / c x=0.00069$

- $k_{s} / c x=0.00164$

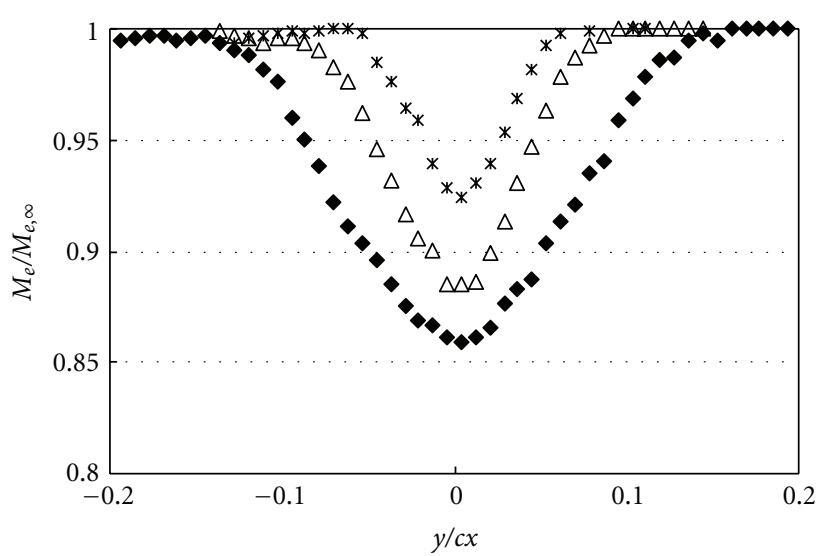

(b)

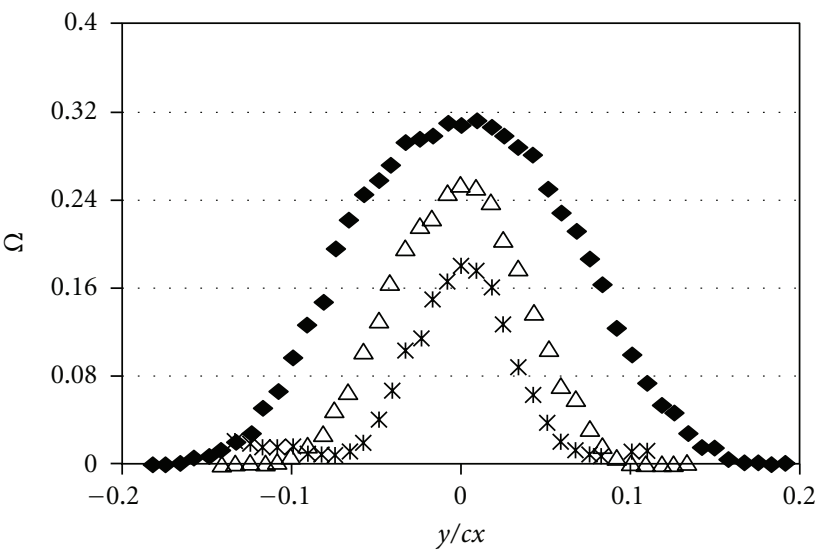

$* k_{s} / c x=0$

$\Delta k_{s} / c x=0.00069$

- $k_{s} / c x=0.00164$

(c)

(d)

FIgURE 5: Profiles measured with $M_{e, \infty}=0.9$ and $T u=0.9 \%$ for the symmetric airfoil [8]. (a) Normalized local total pressure losses. (b) Normalized local Mach numbers. (c) Normalized local kinetic energy. (d) $\Omega$ total pressure loss coefficient.

[8]. With a similar experimental condition, Jackson et al. [54] report similar $C_{p, \infty}$ values which result from strong oblique shock waves at the airfoil trailing edge with angles relative to the axial direction of about 73 degrees. With roughness on the airfoil surface, the boundary layers which develop along the airfoil are much thicker. As a result, blockage of the flow in the airfoil passage is increased, with less flow expansion as it advects through the test section passage. Consequently, the Mach number along the roughened airfoil is different, the flow in the passage is entirely subsonic, and the maximum Mach number is about 0.9 . No trailing edge shock waves are then present at the trailing edge of the roughened airfoil, freestream $C_{p, \infty}$ values are zero, and $P_{o i}$ is approximately equal to $P_{o e, \infty}[8]$.

4.6. Integrated Aerodynamic Losses. In the present investigations, IAL data are normalized using the airfoil passage effective pitch $p$ and test section inlet stagnation pressure
$P_{o i}$ in Figure 6. These data are given as they depend upon $k_{s} / c x$ for different $T u$ values, for the airfoils with the smooth surfaces $\left(k_{s} / c x=0\right)$, small-sized roughness $\left(k_{s} / c x=\right.$ $0.00069)$, and large-sized roughness $\left(k_{s} / c x=0.00164\right)$. The total pressure at the inlet of the test section $P_{o i}$ is $195 \mathrm{kPa}$, and the corresponding exit freestream Mach number, measured one chord length downstream of the airfoil trailing edge, is 0.9 . Note that when the turbulent intensity levels increase from 0.9 percent to 5.5 percent, dimensional IAL magnitudes decrease for all three cases with airfoils with different surface roughness. Different trends for various $k_{s} / c x$ values are found as the turbulent intensity levels increase from 5.5 percent to a much higher value, 16.2 percent. For the smooth airfoil, dimensional IAL values continuously decrease as the magnitude of the inlet turbulence intensity increases. For the airfoil with the small-sized roughness $\left(k_{s} / c x=0.00069\right)$, the dimensional magnitudes of IAL become less sensitive to $T u$ and are nearly kept constant while $T u$ increases from 


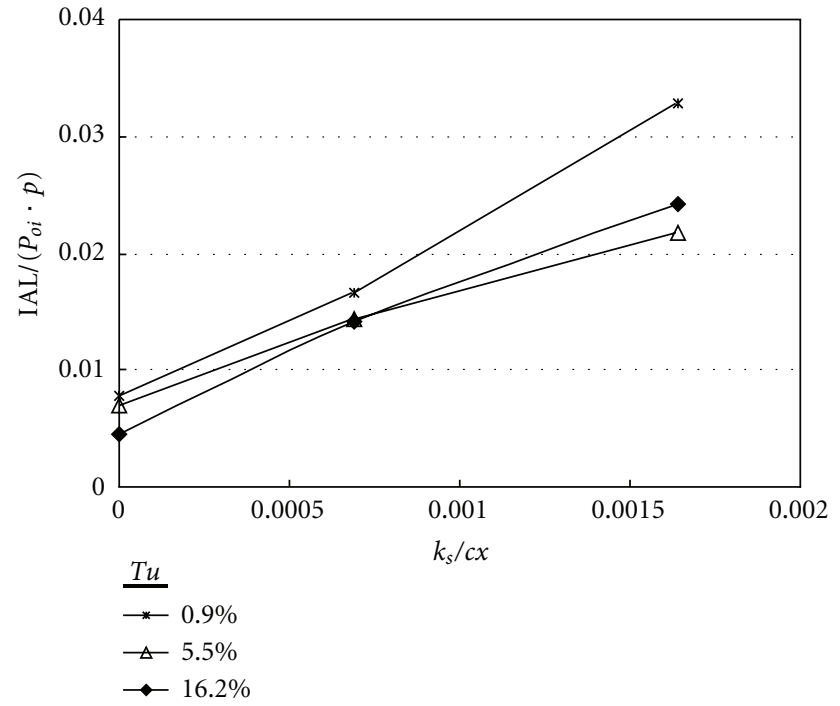

FIGURE 6: Comparison of normalized Integrated Aerodynamic Loss as dependent upon the normalized equivalent sandgrain roughness size for different inlet turbulence intensity levels for $M_{e, \infty}=0.9$ for the symmetric airfoil investigations [8].

5.5 percent to 16.2 percent. For the airfoil with large-sized roughness $\left(k_{s} / c x=0.00164\right)$, dimensional IAL magnitudes increase slightly as the inlet turbulence intensity level gets larger [8]. The overall trends of the normalized data in Figure 6 illustrate the dominating influences of airfoil surface roughness on aerodynamic losses and weak dependence of these losses on inlet freestream turbulence intensity level. The data in Figure 6 also show larger normalized IAL variations with $T u$ at the largest $k_{s} / c x$ value, which provides additional evidence that thicker rough-surface boundary layers are more sensitive to changes of freestream turbulence level than thinner boundary layers which develop over smooth surfaces [8].

Figure 7 shows how normalized IAL data vary with exit freestream Mach number for different values of $k_{s} / c x$ for $T u=0.9$ percent. Here, IAL values increase as the exit freestream Mach number increases for each value of $k_{s} / c x$. This is consistent with results from Arts [34] and $\mathrm{Xu}$ and Denton [9], whose experimental and analytical results show that total pressure losses increase approximately with the square of the Mach number. Figure 7 also shows that the largest IAL magnitude increases are present with the largesized roughness $\left(k_{s} / c x=0.00164\right)$. Overall, such data further illustrate different dependence of aerodynamic losses on exit freestream Mach number, which occur as the level of airfoil surface roughness changes.

\section{Symmetric Airfoils with Film Cooling}

This investigation employs a test section especially designed to investigate the effects of suction surface film cooling on aerodynamic losses, because of their dominating importance in relation to overall downstream loss magnitudes $[41,46,52$, 53]. A symmetric airfoil is employed with the same transonic

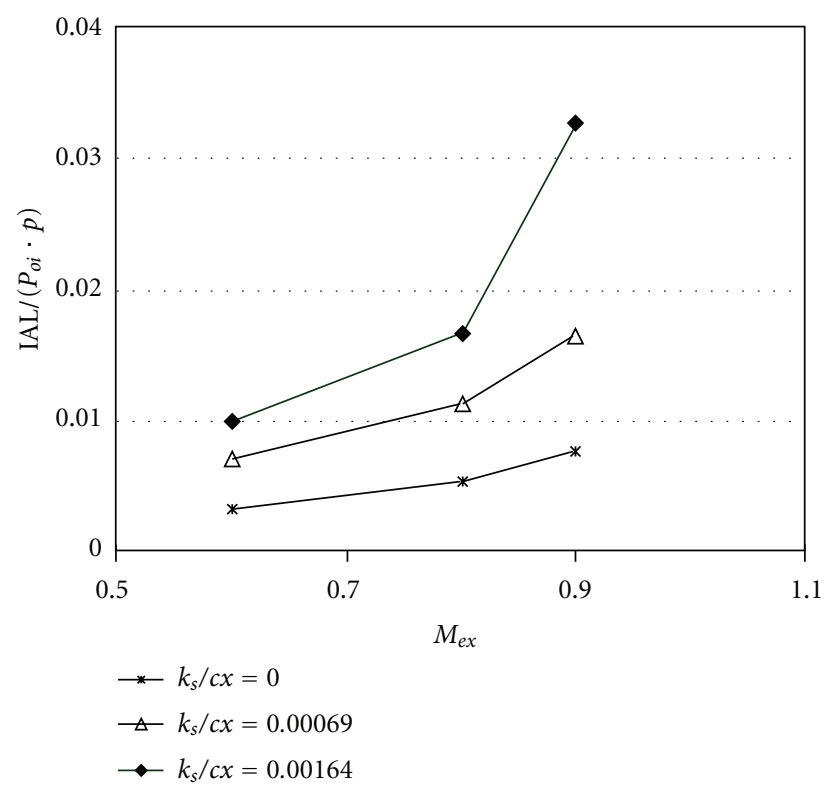

FIGURE 7: For $T u=0.9 \%$, comparison of normalized Integrated Aerodynamic Loss as dependent upon the exit Reynolds number for the smooth airfoil $\left(k_{s} / c x=0\right)$, the airfoil with small roughness $\left(k_{s} / c x=0.00069\right)$, and the airfoil with large roughness $\left(k_{s} / c x=\right.$ $0.00164)$ for the symmetric airfoil investigations [8].

Mach number distribution on both sides. Mach numbers along the airfoil surface range from 0.4 to 1.24 and match values on the suction surfaces of airfoils from operating aeroengines. Thus, the distribution of Mach numbers is similar to the distribution for $P_{o i}=195 \mathrm{kPa}$, which is presented in Figure 2. The magnitude of longitudinal turbulence intensity at the test section inlet is 0.9 percent. Integrated Aerodynamic Loss IAL magnitudes are determined from measurements of total pressure loss coefficients, which are made one chord length downstream of the airfoil [54].

Film cooling holes are located on one side of the airfoil near the passage throat where the freestream Mach number is nominally 1.07 . Two different film cooling configurations are investigated $(\mathrm{CDH}$, conical diffused holes, and $\mathrm{RCH}$, round cylindrical holes), with density ratios from 0.82 to 1.23 over a range of blowing ratios. Results are given for both "ambient" and "cold" film cooling, which correspond to coolant to mainstream density ratios of $0.82-0.95$, and $1.01-$ 1.23 , respectively [54].

The results thus provide insight into the mechanisms for total pressure losses due to suction surface film cooling, in order to isolate these phenomena without the complicating influences of flow turning or the collection of vortices ordinarily present in turbine passages due to this turning [54].

5.1. Test Section and Film Cooling Hole Geometries. A schematic diagram of the nonturning airfoil cascade test section is shown in Figure 8(a). This is the same facility arrangement that is utilized by Zhang and Ligrani [8], and Zhang et al. [5-7]. A schematic diagram of the cross-section 


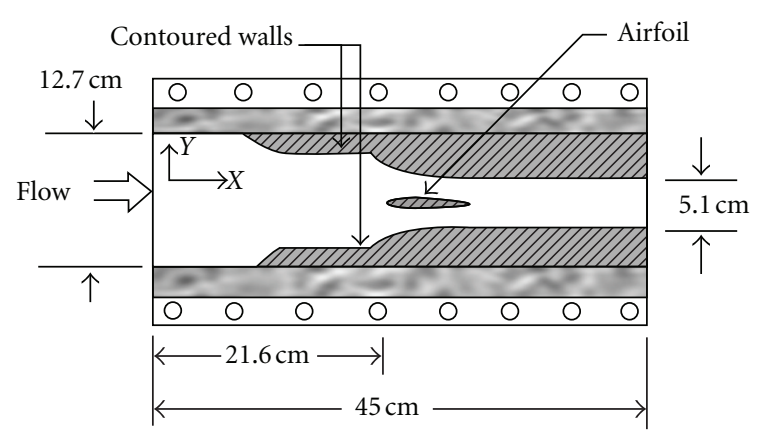

(a)

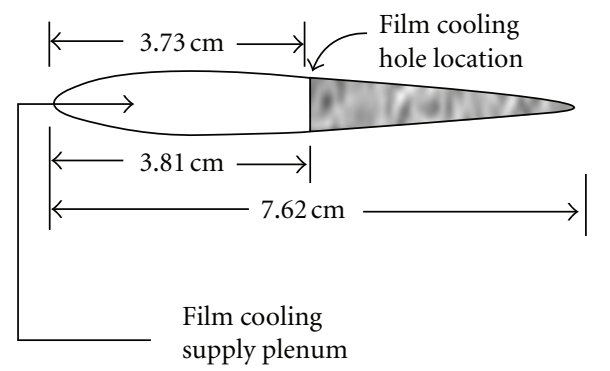

(b)

Figure 8: Schematic diagrams of the (a) test section, and (b) test airfoil, for the investigations utilizing symmetric airfoils with film cooling [54].

of one symmetric airfoil tested is shown in Figure 8(b). The airfoil chord length is $7.62 \mathrm{~cm}$. The effective pitch is $5.08 \mathrm{~cm}$. The trailing edge of the symmetric airfoil is a $1.14 \mathrm{~mm}$ radius round semicircle, designed to produce the wake flows of turbine airfoils employed in operating engines. The symmetric airfoil shape is employed to provide sufficient interior space for a plenum for film cooling injection, while maintaining appropriately scaled injection hole diameter and trailing edge thickness.

The two hole configurations studied are $\mathrm{CDH}$-conical diffused holes, and RCH-round cylindrical holes. In each case, one row of 21 holes is employed with spanwise spacing of 4 hole metering diameters, at a location $3.73 \mathrm{~cm}$ or $0.49 c x$ from the airfoil leading edge. Each hole in the $\mathrm{CDH}$ geometry is diffused axisymmetrically about its axis. The entrance diameter and length to entrance diameter ratio of both types of holes are the same, $.068 \mathrm{~cm}$ and 2.26 , respectively.

The present test section is useful and advantageous over cascade arrangements with multiple airfoils and significant flow turning for the same issues mentioned earlier, and because the results obtained with the arrangement are not configuration dependent. As such, the present experiment is designed to isolate the effects of suction surface film cooling on wake aerodynamic losses, while matching Reynolds numbers, Mach numbers, pressure gradients, passage flow rates, boundary layer development, and physical dimensions of airfoils in operating engines.
5.2. Secondary Air Injection System. The air used for film cooling first enters a Norman Filters 5 micron ABS particulate filter, a Fairchild no. 10282 pressure regulator, a sonic orifice, a Wilkerson M16-02 F00B E95 coalescing filter, a Wilkerson X03-02-000A J96 Desiccant dryer, a Dwyer Model RMC series rotameter, and a pressure relief valve. For every experimental test condition, the injectant mass flow rate measured with the sonic orifice is in excellent agreement with the flow rate measured with the rotameter. The dryers and filters are required to avoid frost build since a Xchanger Inc. TV-050 heat exchanger uses liquid nitrogen to cool injectant air to temperatures as low as $-120^{\circ} \mathrm{C}$.

5.3. Pressure and Temperature Measurements. As tests are conducted, Validyne Model DP15-46 pressure transducers (with diaphragms rated at either $345 \mathrm{kPa}$ or $1380 \mathrm{kPa}$ ), and calibrated copper-constantan thermocouples are used to sense pressures and temperatures at different locations throughout the facility, including throughout the injection air supply system. Signals from the transducers are processed by Celesco Model CD10D carrier demodulators. All pressure transducer measurement circuits are calibrated using a Wallace and Tiernan FA145 bourdon tube pressure gage as a standard. A United Sensor PLC-8-KL pitot-static probe with an attached copper-constantan thermocouple and a fourhole conical-tipped pressure probe with an attached copperconstantan thermocouple are used to sense total pressure, static pressure, and recovery temperature at the inlet and exit of the test section, respectively, during each blow down. The conical probe is aligned using two yaw ports placed on either side of the probe. As a blow down is underway, the probe is located one chord length downstream of the airfoil. It is traversed using a two-axis traversing sled with two Superior Electric M092-FF-206 synchronous stepper motors, connected to a Superior Electric Model SS2000I programmable motion controller and a Superior Electric Model SS2000D6 driver. These are interfaced and controlled by a Hewlett-Packard 362 series computer. Additional details are provided by Jackson et al. [54].

5.4. Aerodynamic Losses due to Trailing-Edge Shock Waves. Here, aerodynamic losses due to trailing-edge shock waves are considered for the uncooled airfoil, as well as for the film cooled airfoil. Measurements of $C_{p}$ distributions with $y / c$ show that wake total pressure deficits extend to $y / c= \pm 0.07$ from the airfoil symmetry line at $y / c=0$. Outside of this region, in the freestream, magnitudes of $P_{\text {oi } \infty}-P_{o e \infty}$ are nonzero, ranging from 0.3 to $1.6 \mathrm{kPa}$ (which correspond to $C_{p}$ from 0.002 to 0.007 ) because of the pair of trailing edge oblique shock waves shown in Figure 3. Thus, the influences of the trailing-edge shock waves on stagnation pressure losses are determined based on variations of data measured in the freestream flow.

Magnitudes of freestream pressure coefficient $C_{p \infty}$, deduced from these freestream pressures, are given as dependent upon blowing ratio in Figure 9. These data thus represent aerodynamic losses due to the trailing edge oblique shock waves only. The most important trend in this figure 


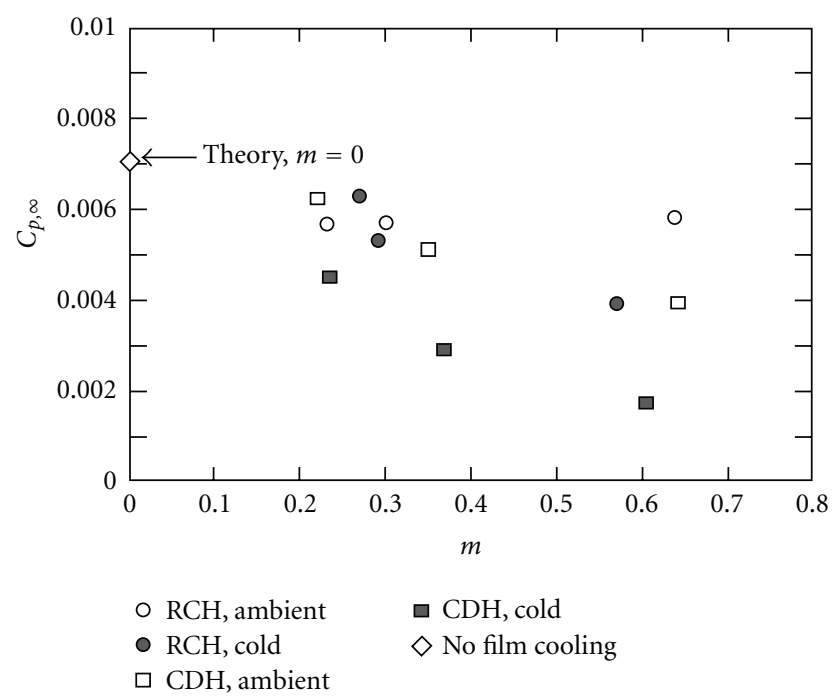

FIgURE 9: Normalized total pressure losses in the freestream flow due to trailing edge, oblique shock waves as dependent upon blowing ratio for round cylindrical holes ( $\mathrm{RCHs}$ ) and conical diffused holes (CDHs), for the symmetric airfoil with film cooling [54].

is the decrease of $C_{p \infty}$ with $m$ for "ambient" and "cold" $\mathrm{CDH}$ injection as well as for "cold" $\mathrm{RCH}$ injection. Values with film cooling are also lower than the $m=0$ no-film cooling value, which is in agreement with oblique shock wave theory given by Anderson [68]. As $C_{p \infty}$ decreases with increasing $m$, shock wave angles (measured relative to the airfoil symmetry plane) become increasingly larger than $73^{\circ}$ (the no-film cooling value evidenced by the numerical results in Figure 3). This happens because the film increases the effective thickness of the airfoil trailing edge, which results in less expansion through the airfoil passage. As a result, the flow deflection angle at the trailing edge decreases, along with Mach numbers downstream of film hole locations. The trailing edge shock waves are thus weakened by $\mathrm{CDH}$ film cooling and "cold" $\mathrm{RCH}$ film cooling as blowing ratio increases since normalized total pressure drops across them are smaller. Eventually, the oblique shock waves disappear as shock wave angles approach $90^{\circ}$. Figure 9 shows that the largest $C_{p \infty}$ decreases with blowing ratio occur with $\mathrm{CDH}$ films rather than with $\mathrm{RCH}$ films. This is because larger concentrations of $\mathrm{CDH}$ film remain closer to the surface as the film advects to the airfoil trailing edge. Lower $C_{p \infty}$ values and weaker oblique shock waves also result as the density ratio increases since lower momentum flux ratios enhance this effect.

5.5. Integrated Aerodynamic Losses. In determining magnitudes of the integrated aerodynamic losses, IAL, contributions from the oblique shock waves in the freestream are removed from total pressure profiles. This is accomplished by subtracting off the constant freestream value of $\left(P_{\text {oi }}-\right.$ $\left.P_{o e \infty}\right) / P_{o i \infty}$ throughout each $C_{p}$ profile. This gives corrected profiles of $\left(P_{o e \infty}-P_{o e}\right) / P_{o i \infty}$, which, of course, equal zero in the freestream. Profiles of $\left(P_{o e \infty}-P_{o e}\right)$ are then integrated with respect to $y$ to determine IAL values at each film injection flow condition. IAL magnitudes thus represent mixing losses only without the contributions of the shock waves [54].

Such IAL magnitudes are presented in Figure 10 as dependent upon Mach number ratio, $M_{c} / M_{\infty}$. Included is the integrated aerodynamic loss magnitude for no-film cooling at $M_{c} / M_{\infty}=0$. Here, $M_{\infty}$ is the local freestream Mach number at the exit locations of the film cooling holes. In all cases, values measured with film cooling are higher than the no film cooling value. Figure 10 shows important variations with film cooling hole geometry since integrated losses measured downstream of $\mathrm{RCH}$ are substantially higher than $\mathrm{CDH}$ magnitudes (when compared at the same Mach number ratio $M_{c} / M_{\infty}$ ). The two hole configurations additionally show different dependencies on the density ratio. IAL values measured downstream of $\mathrm{CDH}$ increase continuously with $M_{c} / M_{\infty}$ with about the same magnitudes for "ambient" and "cold" film injection. In contrast, $\mathrm{RCH}$ integrated aerodynamic losses increase with density ratio at each $M_{c} / M_{\infty}$ [54].

The same data are shown in normalized form after subtracting off the IAL value for no-film cooling in Figure 11. Values are compared with the one-dimensional mixing loss equation given by

$$
\frac{\left(\mathrm{IAL}-\mathrm{IAL}_{\mathrm{NFC}}\right)}{p P_{\text {oi } \infty}}=C_{1}\left[\frac{k M_{\infty}^{2}}{2}\right]\left(\frac{\dot{m}_{c}}{\dot{m}_{\infty}}\right) B,
$$

where $C_{1}=0.76$ for $\mathrm{CDH}$ and $C_{1}=2.48$ for $\mathrm{RCH}$, and

$$
B=\left[1+\frac{T_{o c}}{T_{o i \infty}}-\left[2\left(\frac{u_{c}}{u_{\infty}}\right) \cos \theta\right]\right] .
$$

This equation is similar to one given by Denton [41]. In both cases, $M_{\infty}$ and $u_{\infty}$ are freestream values at the streamwise locations of the film cooling holes. Equation (17) shows good agreement with $\mathrm{CDH}$ data in Figure 11, including its dependence on density ratio, for blowing ratios $m$ greater than 0.3 . The correlating equation also shows agreement with most of the $\mathrm{RCH}$ data, including its dependence on density ratio since "ambient" values are higher than "cold" values at each $m$. The decrease of RCH "ambient" data as $m$ increases (for $m>0.6$ in Figure 11) is consistent with data presented by Kubo et al. [52], as well as with measured $C_{P}$ profiles [54].

\section{Cambered Vanes with No-Film Cooling}

The present work on turbine vanes with no film cooling is unique because new data are provided to clarify the separate and combined influences of Mach number and freestream turbulence level on aerodynamic performance of a cambered turbine vane. Considered are the effects of freestream turbulence on aerodynamic losses downstream of the smooth vane for three different Mach number distributions, one of which results in transonic flow (and matches flow conditions in the application). A fine mesh grid and crossbars are used to augment the magnitudes of longitudinal turbulence intensity at the inlet of the test 


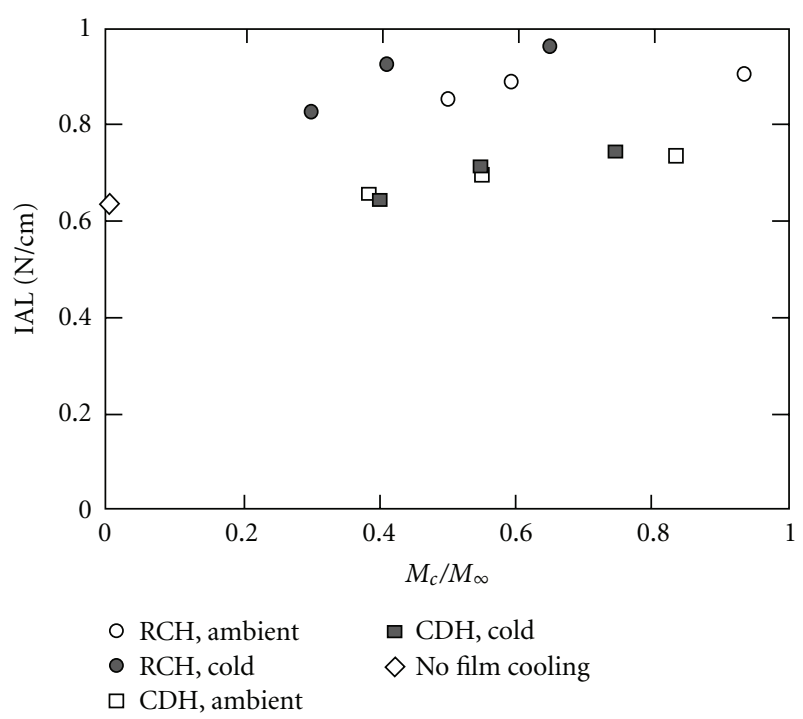

Figure 10: Comparison of integrated aerodynamic losses as dependent upon Mach number ratio from round cylindrical holes (RCHs) and conical diffused holes $(\mathrm{CDH})$, after correction for the presence of trailing edge oblique shock waves, for the symmetric airfoil with film cooling [54].

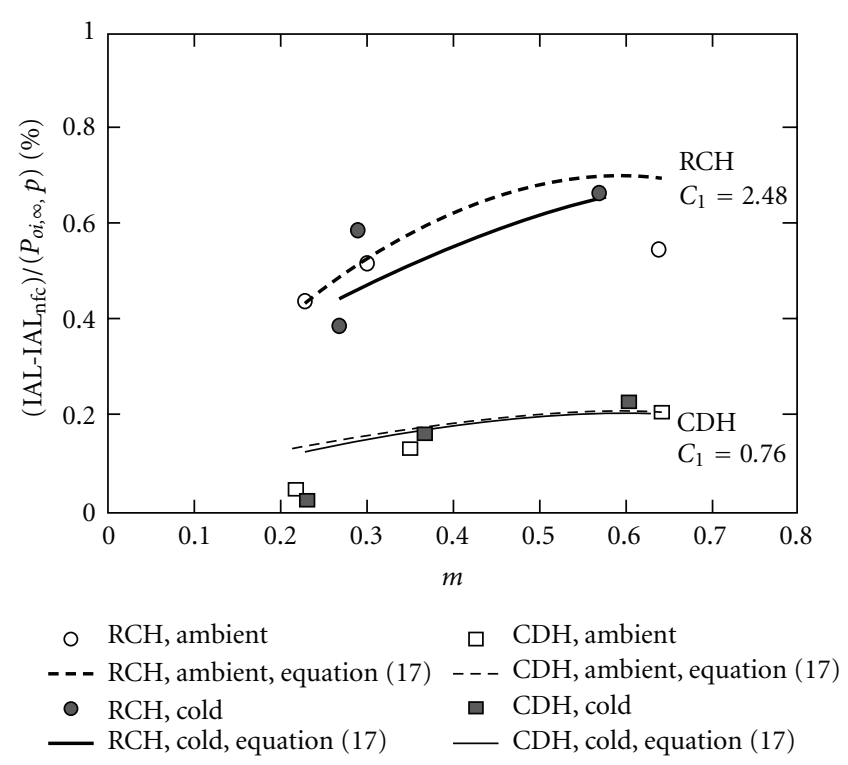

Figure 11: Comparison of normalized integrated aerodynamic losses relative (minus-integrated aerodynamic losses with no film cooling) at different blowing ratios (after correction for the presence of trailing edge oblique shock waves) with correlating equation (17) for the symmetric airfoil with film cooling [54].

section. Additional details on experimental apparatus and procedure details are provided by Zhang et al. [37, 38], and Zhang and Ligrani [27, 39, 40]. Wake profile data are presented for two different locations downstream the vane trailing edge, which illustrate the influences of varying freestream turbulence intensity level, surface roughness, and vane Mach number on local aerodynamic losses, Integrated
Aerodynamics Losses (IAL), area-averaged loss coefficients, and mass-averaged loss coefficients.

6.1. Test Section and Test Vane. The present test section is designed to match Reynolds numbers, Mach numbers, pressure gradients, passage mass flow rates, boundary layer development, streamline curvature, airfoil camber, and physical dimensions of turbine vanes in operating industrial engines. A schematic diagram of the test section with the cambered vane is shown in Figure 12. The inlet of the test section is $12.70 \mathrm{~cm}$ by $12.70 \mathrm{~cm}$. Appropriate cascade flow conditions are maintained, in part, by a pair of adjustable bleed ducts which are located on the two side walls, as shown in Figure 12. The flow rate of each bleed duct is regulated using an adjustable ball valve. Following these, the test section walls have the same pressure side and suction side contours as the test vane. The exit area and exit flow direction from the cascade test section can be altered by changing the angles of the two exit tailboards, which are also shown in Figure 12. The true chord of the vane is $7.27 \mathrm{~cm}$, the axial chord is $4.85 \mathrm{~cm}$, the pitch is $6.35 \mathrm{~cm}$, the span is $12.7 \mathrm{~cm}$, and the flow turning angle is 62.75 degrees.

6.2. Test Section Flow Characteristics and Mach Number Distributions. During each blow-down test, the inlet total pressure at the inlet of the test section $P_{o i}$ is kept constant at one of the different values, at either $94 \mathrm{kPa}, 98 \mathrm{kPa}$ or $106 \mathrm{kPa}$. Corresponding exit freestream Mach numbers, measured 0.25 axial chord lengths downstream of the airfoil trailing edge, are $0.35,0.50$, and 0.71 , respectively, and chord Reynolds numbers (based on exit flow conditions) are $0.5 \times$ $10^{6}, 0.7 \times 10^{6}$, and $0.95 \times 10^{6}$, respectively. Magnitudes of the inlet longitudinal turbulence intensity (as a percentage) for an exit Mach number of 0.35 are 1.6, 5.7, and 8.2 for nogrid, fine-mesh grid, and bar grid, respectively. Respective values for an exit Mach number of 0.50 are 1.2, 5.4, and 7.7. Respective values for an exit Mach number of 0.71 are then $1.1,5.4$, and 7.7. Here, turbulence intensity is defined as the ratio of the root-mean square of the longitudinal fluctuation velocity component divided by the local streamwise mean component of velocity [37].

Figure 13 shows the Mach number distributions along the turbine vane pressure side and along the vane suction side for each of the three operating conditions. Figure 13 shows that the Mach number distributions on pressure and suction sides for $M_{e x}=0.71$ are in excellent agreement with data from an operating gas turbine engine. This particular Mach number distribution is transonic on the vane suction side and subsonic on the pressure side. The Mach number distributions in Figure 13 for the other two operating conditions are completely subsonic [37].

6.3. Pressure and Temperature Measurements. As tests are conducted, Validyne Model DP15-46 (36) pressure transducers (with diaphragms rated at $13.8,34.5 \mathrm{kPa}$ or $344.7 \mathrm{kPa}$, resp.) and calibrated copper-constantan thermocouples are used to sense pressures and temperatures at different locations throughout the facility. A United Sensor PLC-8KL pitot-static probe with an attached, calibrated Watlow 


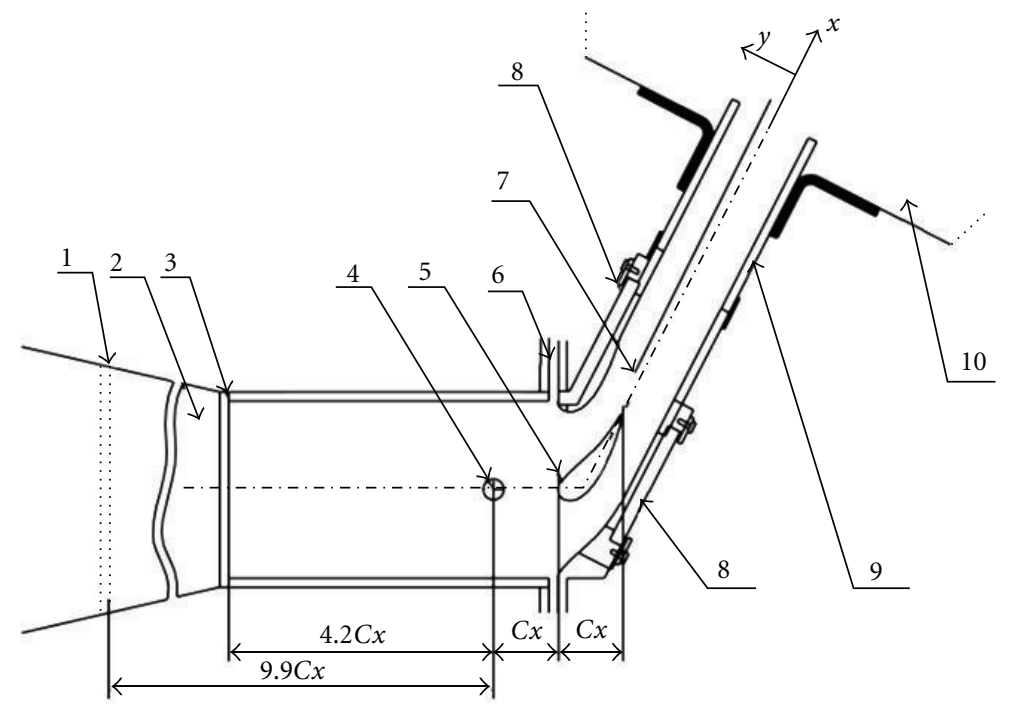

(1) Bar grid position

(2) Nozzle

(3) Fine mesh grid position

(4) Inlet pressure probe and thermocouplet

(5) Test blade

(6) Bleeding system

(7) Exit pressure probe and thermocouple

(8) Zinc-selenide window

(9) Tailboard

(10) Exit plenum

Figure 12: Schematic diagram of the test section [27, 37-40].

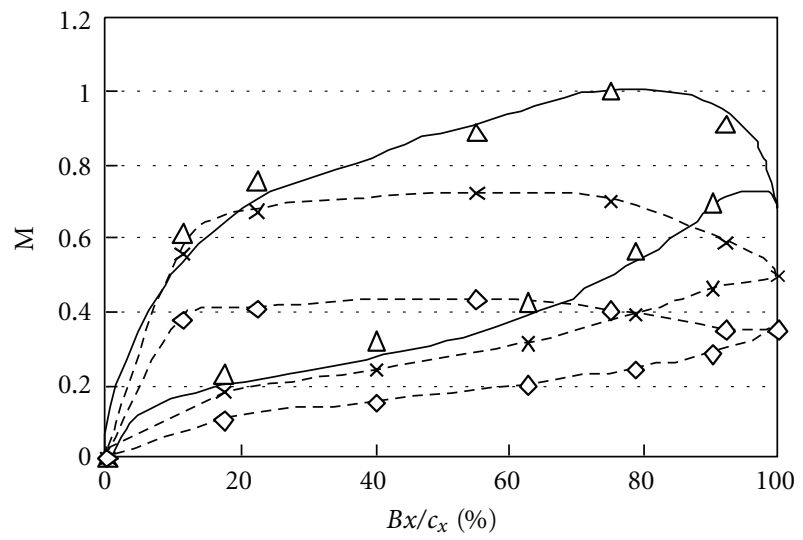

— Data from an industrial application

$\triangle \quad M_{e x}=0.71$

-*- $M_{e x}=0.5$

$-\diamond-M_{e x}=0.35$

FIGURE 13: Mach number distributions along the test cambered vane [37]. standard type-K copper-constantan thermocouple and a four-hole conical-tipped pressure probe also with a similar thermocouple are used to sense total pressure, static pressure, and recovery temperature at the inlet and exit of the test section, respectively, during each blowdown. Mach numbers, sonic velocities, total temperatures, and static temperatures are determined from these data. The four-hole probe has a tip which is $1.27 \mathrm{~mm}$ in diameter, and a stem which is $3.18 \mathrm{~mm}$ in diameter. Each port has a diameter of $0.25 \mathrm{~mm}$. The overall response time of the pressure measuring system is about 0.2 seconds. The conical probe is aligned using two yaw ports placed on either side of the probe. The probe is located downstream of the vane. The position in the streamwise direction is adjustable. As a blow down is underway, it is traversed across a full pitch using a two-axis traversing sled with two Superior Electric synchronous stepper motors, connected to a Superior Electric programmable motion controller and a Superior Electric driver. Commands for the operation of the motion controller are provided by LABVIEW 7.0 software and pass through a serial port after they originate in a Dell Precision 530 PC workstation. Each profile is measured through the wake from minus $y / c x$ locations to positive $y / c x$ locations, and then repeated as the 


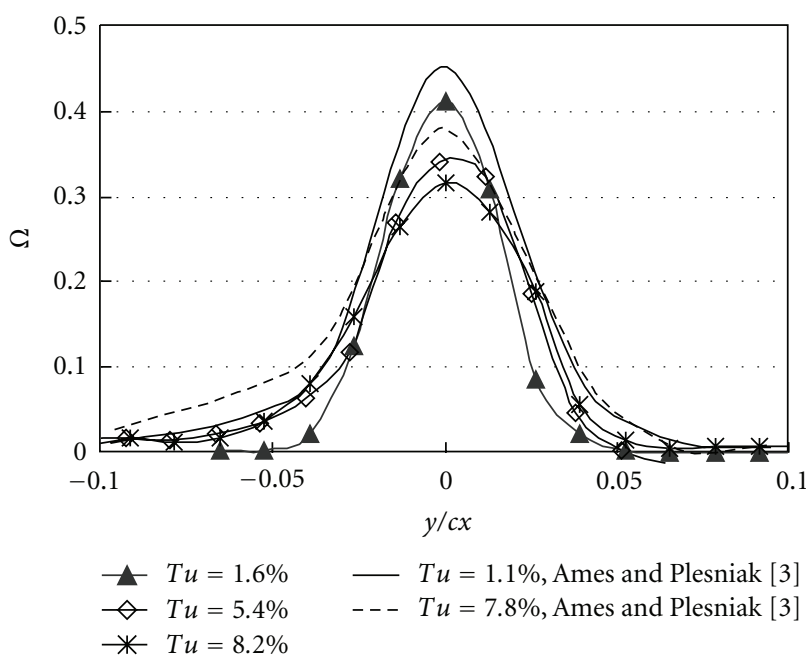

Figure 14: Comparison of vane wake total pressure loss coefficient profiles with similar data from Ames and Plesniak [3]. The present data are measured 0.25 axial chord lengths downstream of a cambered vane with $M_{e x}=0.35$ [37].

probe is traversed in the opposite direction. The resulting data are subsequently averaged at each wake measurement location.

Voltages from the carrier demodulators and thermocouples are read sequentially using Hewlett-Packard HP44222T and HP44222A relay multiplexer card assemblies, installed in a Hewlett-Packard HP3497A low-speed Data Acquisition/Control Unit. This system provides thermocouple compensation electronically such that voltages for type $\mathrm{T}$ thermocouples are given relative to $0^{\circ} \mathrm{C}$. The voltage outputs from this unit are acquired by the Dell Precision 530 PC workstation through its USB port, using LABVIEW 7.0 software and a GPIB-USB-B adaptor made by National Instruments.

6.4. Local Aerodynamic Performance. Figure 14 presents local aerodynamic performance data ( $\Omega$ total pressure loss coefficients) in the wake for three freestream turbulence intensity levels, which are measured in the wake at 0.25 axial chord lengths downstream of the vane.

Figure 15 shows the effects of surface roughness on normalized local total pressure losses $C_{p}$, normalized local Mach numbers $M_{e} / M_{e, \infty}$, normalized local kinetic energy KE, and $\Omega$ total pressure loss coefficients for $M_{e x}=0.71$. Rough surface characteristics for the vane are given in Table 2. Here, surface roughness characteristics are determined in the same manner as for the symmetric airfoil. These data are measured in the wake at one axial chord length downstream of the vane. To provide an appropriate standard of comparison, each profile is measured over one complete exit pitch spacing (or one complete exit vane spacing). The different profiles provide information on local wake deficits of total pressure, Mach number, and kinetic energy. Data are given for a smooth vane, and vanes with uniform small-sized roughness $\left(k_{s} / c x=0.00108\right)$, uniform large-sized roughness $\left(k_{s} / c x=\right.$
0.00258), and variable roughness. The inlet total pressure is kept constant at $106 \mathrm{kPa}$ to maintain the same operating condition.

The wake profiles shown in Figures 14 and 15 are asymmetric [37]. Suction side wakes (at negative $y / c x$ ) are thicker than the pressure side wakes (at positive $y / c x$ ). The asymmetry in the wake is due to loading on the vane surface, and the past history of the flow. In addition, the growth and development of boundary layers on the suction and pressure sides are different. On the suction side, where local freestream velocities are higher, the boundary layers continue to become thicker up to the trailing edge. The thicker boundary layers then separate from the suction surface of the vane, which affects wake behavior immediately downstream of the trailing edge. In contrast, on the pressure side, boundary layers decrease in thickness in the back section of the vane contour as a result of locally higher flow acceleration [37]. Bammert and Sandstede [21] report data showing that the boundary layer on the suction side is considerably thicker than on the pressure side. According to them, wake profile losses are determined more by suction side events by a factor about 2.5 to 3.5 times compared to events originating near the pressure side.

In their low-speed cascade experiments, Ames and Plesniak [3] also observe wake broadening with increasing mainstream turbulence intensity and associate these with smaller peak velocity deficits. The Ames and Plesniak [3] data are taken approximately 0.3 axial chord lengths downstream of a vane with $M_{e x}=0.27$, compared to 0.25 axial chord lengths downstream of a vane with $M_{e x}=0.35$ for the Zhang et al. [37, 38] results. The vane used by Ames and Plesniak is two times the size of the vane from present study, and has an exit angle of $72.4^{\circ}$, compared to an exit angle of $62.75^{\circ}$ for the Zhang et al. [37, 38] results. Figure 14 shows that the two sets of data have similar trends and similar qualitative variations with $\mathrm{Tu}$. In particular, both sets of data show decreasing $\Omega$ magnitudes (see (2)) at $y / c_{x}=0$, and broader wakes with higher $\Omega$ magnitudes at negative $y / c x$, as $T u$ becomes larger. The small quantitative differences are due to slightly different vane configurations, flow conditions, and measurement locations relative to the vane trailing edges. Overall, the agreement between the two data sets not only provides verification of procedures and results from the present study, but also confirms the effects of inlet turbulence intensity level on vane aerodynamic losses in near-wake profiles for similar experimental conditions. Note that freestream losses are present outside of the suction side wakes (at negative $y / c x$ ) in both investigations when inlet turbulence intensity levels are augmented [3, 37, 38].

Figure 15 shows that total pressure losses, Mach number deficits, deficits of kinetic energy, and $\Omega$ total pressure loss coefficients all increase at each $y / c x$ location within the wake as $k_{s} / c x$ increases, provided that the roughness on the surfaces is uniform. The boundary layers along the vane surfaces are thickened as $k_{s} / c x$ increases, which is accompanied by higher magnitudes of Reynolds stress tensor components, higher magnitudes of local turbulent transport, and higher surface skin friction coefficients. The broader 


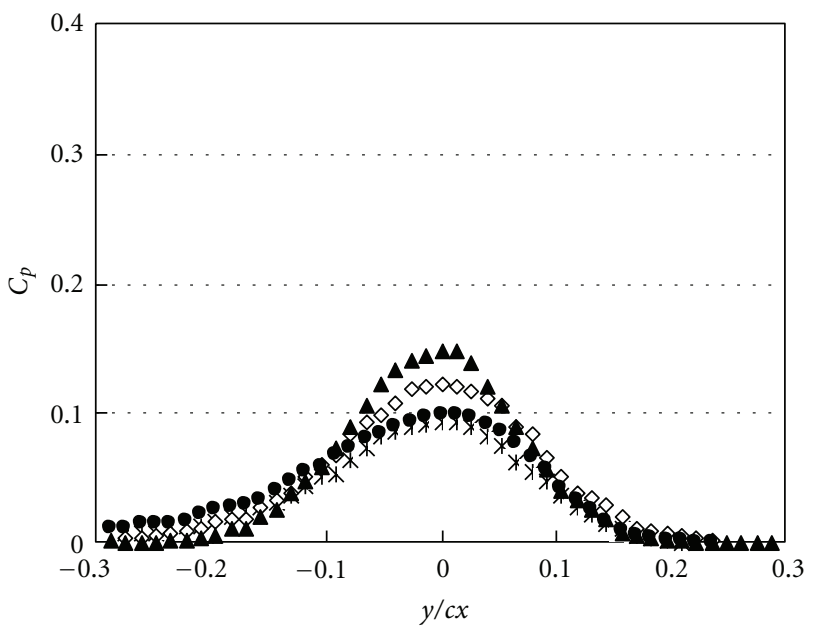

(a)

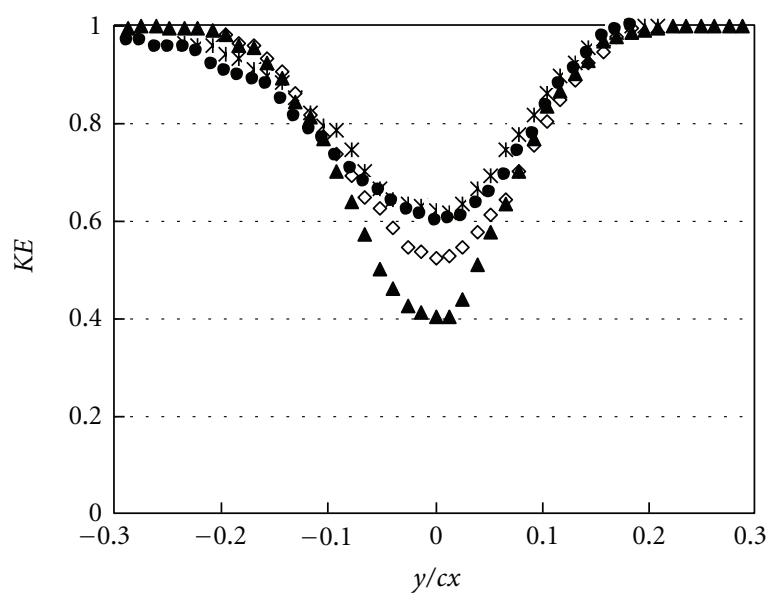

$$
\begin{array}{ll}
* k_{s} / c x=0 & \bullet k_{s} / c x=0.00258 \\
\Delta k_{s} / c x=0.00108 & \bullet \text { Variable roughness }
\end{array}
$$

(c)

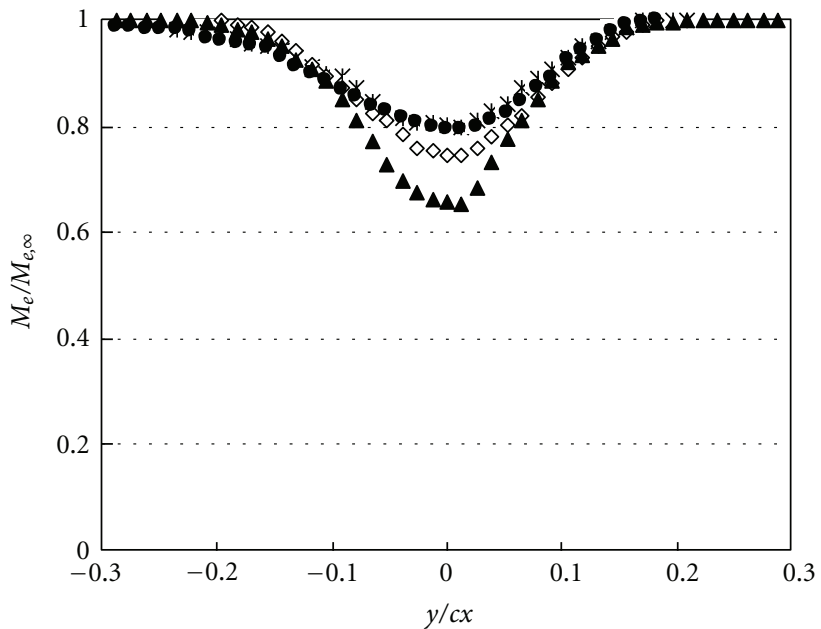

(b)

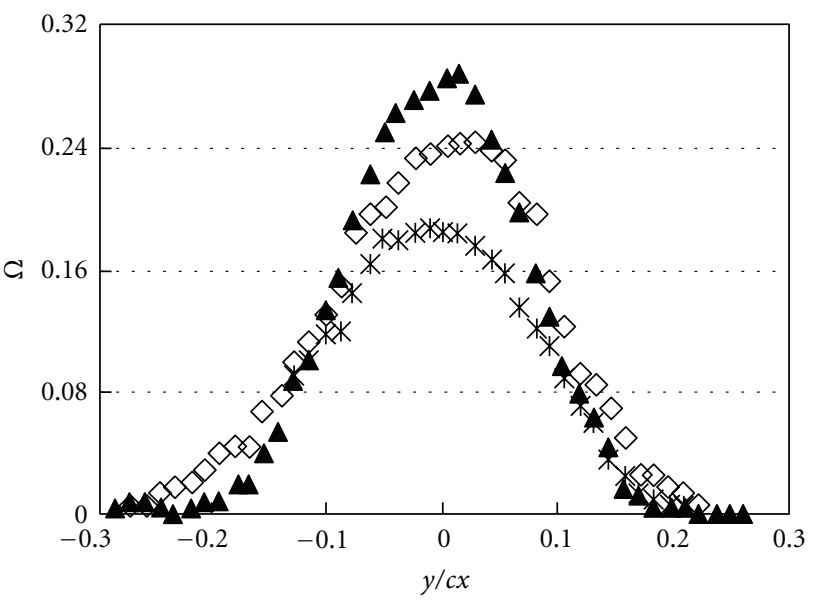

$$
\begin{aligned}
& * k_{s} / c x=0 \\
& \Delta k_{s} / c x=0.00108
\end{aligned}
$$

- $k_{s} / c x=0.00258$

\begin{tabular}{|c|c|c|c|c|c|}
\hline Surface & $\Lambda_{s}$ & $k_{s} / k$ & $k(\mu \mathrm{m})$ & $k_{s}(\mu \mathrm{m})$ & $k_{s} / c x$ \\
\hline Smooth & - & .0026 & 3.50 & .0094 & 0 \\
\hline Rough surface with nickel powder T1166F & 20.1 & 1.889 & 27.92 & 52.59 & .00108 \\
\hline Rough surface with nickel powder NI-914 & 15.4 & 1.959 & 64.03 & 125.19 & .00258 \\
\hline Variable rough surface & & & & Reference [38] & \\
\hline Turbine vane from a utility power engine & 43.5 & 1.640 & 40.82 & 62.30 & .00129 \\
\hline
\end{tabular}

- Variable roughness

(d)

FIGURE 15: Profiles measured at one axial chord length downstream of the cambered vane for $M_{e x}=0.71$ [38]. (a) Normalized local total pressure losses. (b) Normalized local Mach numbers. (c) Normalized local kinetic energy. (d) $\Omega$ total pressure loss coefficient.

TABLE 2: Characteristics of rough surfaces employed for the cambered turbine vane investigations [38].

wakes with increased roughness size in Figure 15 are then the result of (i) different boundary layer development with various roughness, such as earlier laminar-turbulent transition, (ii) augmentations mixing and turbulent transport in the boundary layers which develop along the roughened vanes, (iii) thicker boundary layers at the trailing edges of the roughened vanes, and (iv) increased turbulent diffusion in the transverse direction within the wake as it advects downstream.

Within Figure 15, the effects of surface roughness are much less apparent for positive $y / c x$ values, or downstream of the pressure sides of the vanes. This is evidenced by profiles 
for all three $k_{s} / c x$ values $(0,0.00108$, and 0.00258$)$, as well as for the variable roughness vane, which are similar for $y / c x>0.05$. This is partially due to the different growth of boundary layers on the pressure and suction sides for different amounts of surface roughness. Note that the $\Omega$ profiles in Figure 15(d) are qualitatively similar to the $C_{p}$ profiles in Figure 15(a). This is because the static pressure through the wake $P_{s e}$ varies by only a small amount relative to the freestream value $P_{\text {sec }}$.

Figure 15 also includes measurements made downstream of the vane with variable roughness [38]. The arrangement of variable rough surface is based on observations of roughened turbine vanes from industrial applications. From these observations, the suction side is more or less uniform in roughness and remains at or very close to the "as-cast" condition, even after very long operating times. Pressure side roughness, on the other hand, is more variable. Local roughness magnitudes are often the same as on suction side roughness at the leading edge. Local roughness sizes then vary linearly to the full roughness size, which are typically reached at about $40 \%$ of the distance along the pressure surface. Thus, differences in surface roughness characteristics between the suction and the pressured sides can be very significant due to the different flow and operating conditions encountered. There is also a considerable scatter in the roughness patterns both in qualitative and quantitative terms that are present on vanes and blades from operating engines. The configuration of variable roughness investigated is one typical configuration and is described by Zhang et al. [38]. For the present vane, magnitudes of $k_{s}$ for different percentages of distance along the pressure side are as follows: first 10 percent: $k_{s}=0 \mu \mathrm{m}$, second 10 percent: $k_{s}=0-52.6 \mu \mathrm{m}$, third 10 percent: $k_{s}=52.6 \mu \mathrm{m}$, fourth 10 percent: $k_{s}=52.6-125.2 \mu \mathrm{m}$, and last 60 percent: $k_{s}=125.2 \mu \mathrm{m}$.

In most cases, variable surface roughness profile points in Figure 15 lie between the profiles measured with $k_{s} / c x=0$, and $k_{s} / c x=0.00108$ for $y / c x>-0.1$. This is partially due to different rates of boundary layer development as different levels of roughness are encountered along the vane pressure surface. This gives different magnitudes of boundary layer mixing and losses, and a different wake initial condition near the vane trailing edge, compared to vanes with uniformly roughened surfaces. As a result, suction side wake profiles at $y / c x<0$ downstream of the vane with a variable rough surface are widened. Note that suction side wake profiles in Figure 15 are also widened somewhat for the vane with variable roughness, even this vane has a smooth suction side. Overall, the wakes are pushed toward smaller $y / c x$ values as they are advected downstream (i.e., towards the vane suction side), regardless of the level, uniformity, or variability of the roughness along the surfaces of the vanes [38].

6.5. Integrated Aerodynamic Losses. In present study, IAL magnitudes are mostly the result of two phenomena. These are (i) the losses resulting from formation of the boundary layers along the vane surfaces and (ii) the flow separation,

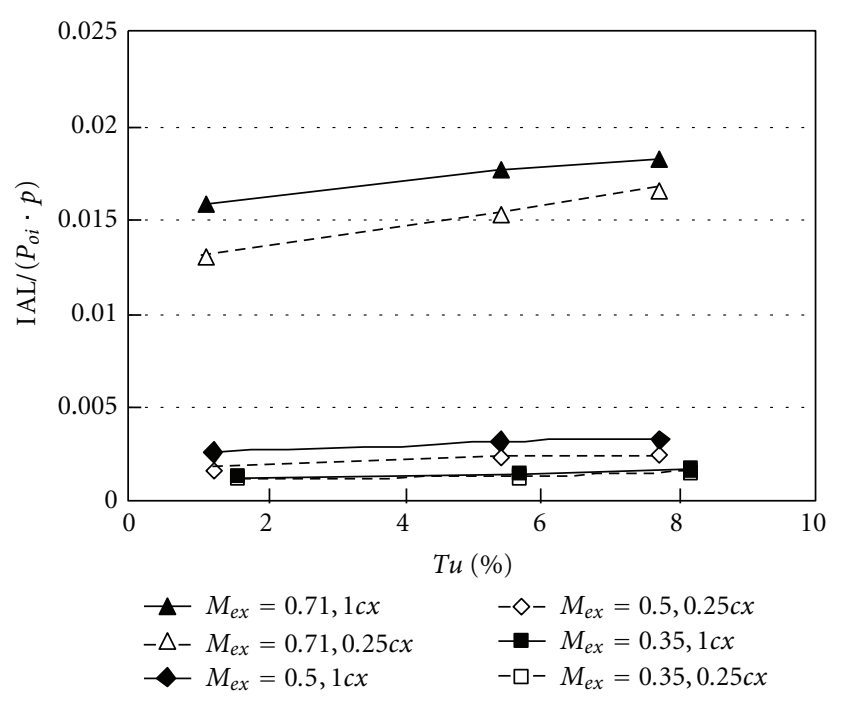

FIGURE 16: Comparison of normalized integrated aerodynamic loss as dependent upon inlet turbulence intensity for a smooth, cambered vane [37].

recirculation zone, and wake mixing losses that are initially present just downstream of the vanes.

IAL data are normalized using the test section passage pitch $p$ and test section inlet stagnation pressure $P_{o i}$ in Figure 16, which shows how IAL data vary with inlet turbulence intensity level for three exit Mach numbers, as measured 0.25 of one axial chord length, and one axial chord length downstream of the turbine vane. For each exit Mach number and each measurement location, the normalized IAL data in this figure increase slightly as the inlet turbulence intensity level increases. The IAL differences at each $M_{e x}$ for the $1 c x$ and $0.25 c x$ downstream measurement locations are relatively small compared to overall IAL loss magnitudes. This is a result of how momentum and turbulence kinetic energy are budgeted and conserved through the wake. Near the vane trailing edge, most turbulence in the wake is initially produced in the separated and recirculating flow zones, which give the initial condition for wake profile development, as well as initial values of turbulence at beginning of the wake. As the wake continues to develop downstream, turbulence decays with streamwise distance because turbulence production is less than diffusion and advection. As a result, the shape of momentum deficit changes mostly due to the transverse diffusion of momentum [37]. Overall magnitudes of total pressure deficits and momentum deficits then do not change greatly as the wake is advected in the streamwise direction because not much mean streamwise momentum is converted into turbulence by local shear and turbulence production $[37,38]$. Such trends in the present data are consistent with results presented by Mee et al. [10], who suggest that most entropy increases take places close to the trailing edge of the airfoils. Additional mixing losses are then only a small fraction of overall loss magnitudes.

IAL dimensional magnitudes, determined from profiles that are measured 0.25 of one axial chord length, and one 


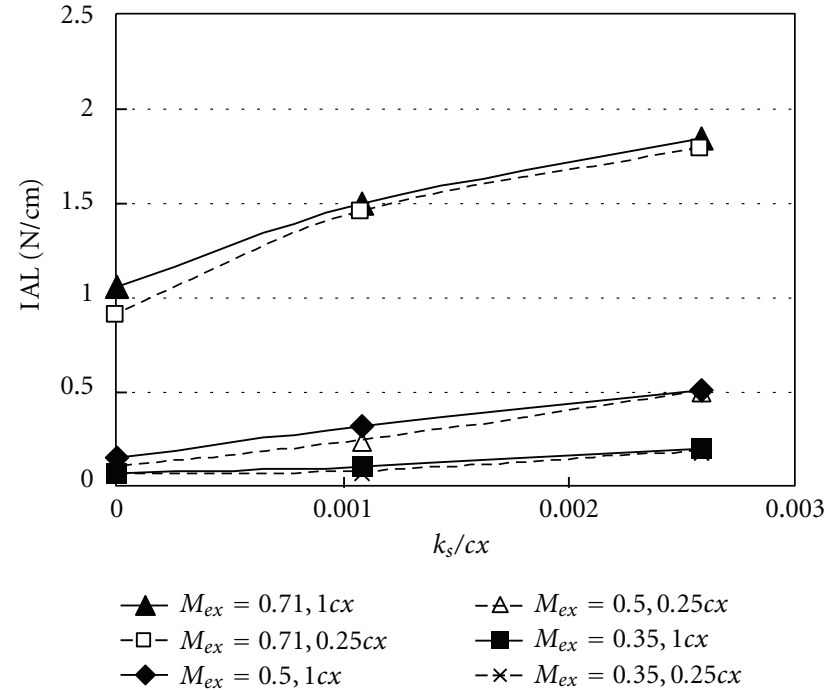

Figure 17: Comparison of dimensional integrated aerodynamic loss as dependent upon the normalized equivalent sandgrain roughness size for $T u=1.1-1.6$ percent for a cambered vane [38].

axial chord length downstream of the turbine vane, are presented in Figure 17 as dependent upon the normalized equivalent sandgrain roughness size for three exit Mach numbers. The overall trends of the data in this figure illustrate the dominating influences, first, of the Mach number distribution along the airfoil (as designated by exit Mach number), and second, of the surface roughness (as characterized by normalized equivalent sandgrain roughness size). For each value of $k_{s} / c x$, dramatic and important IAL magnitude increases are present as higher Mach numbers are present along the airfoil. IAL magnitudes also increase almost linearly as $k_{s} / c x$ increases for each profile measurement location and for each value of exit Mach number [38]. The IAL differences obtained at each $M_{e x}$ for $1 c x$ and $0.25 c x$ are relatively small compared to overall IAL loss magnitudes, which is consistent with the results in Figure 16.

Dimensional IAL magnitudes presented in Figure 18 are determined from profiles that are also measured at two different locations downstream of the test vane trailing edge. The overall trends of the data in this figure further illustrate the dominating influences of the surface roughness on aerodynamic losses, and the weaker dependence of these losses on inlet freestream turbulence intensity level and wake measurement location.

IAL data are normalized using the test section passage pitch $p$ and test section inlet stagnation pressure $P_{o i}$ in Figure 19, which shows how IAL data vary with exit Mach number for different values of $k_{s} / c x$. IAL values increase as the exit Mach number increases for each value of $k_{s} / c x$. This is consistent with results from Zhang and Ligrani $[5,8]$, whose data for a symmetric airfoil are included in Figure 19 and show similar qualitative trends. When compared at the same exit Mach number, the present normalized IAL data for cambered test vanes are then much higher than data obtained downstream of straight symmetric airfoils without

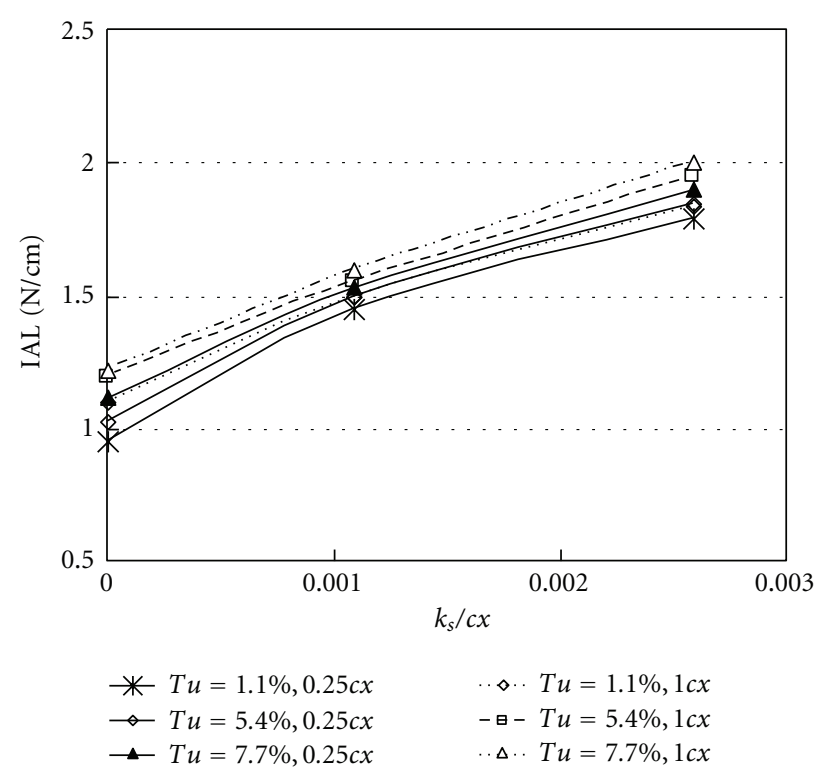

FIgURE 18: Comparison of dimensional integrated aerodynamic loss as dependent on normalized equivalent sand grain roughness size for different inlet turbulence intensity levels, at two different locations downstream of the test vane trailing edge, for a smooth, cambered vane with $M_{e x}=0.71$ [27].

flow turning. This is due to different flow development over the symmetric and cambered airfoils from different pressure gradients and different amounts of streamline curvature which are imposed on airfoil boundary layers. Such imposed pressure gradients are a result of airfoil shape, the imposed Mach number distribution, and streamline curvature and flow turning in the flow outside of the boundary layers. Overall, these results show that greater losses are present with flow turning and cambered airfoils [38].

One data point is included in Figure 19 for the vane with variable roughness. As mentioned, different wake behavior is tied to different rates of boundary layer development, different magnitudes of boundary layer mixing and losses, and a different wake initial condition near the vane trailing edge, compared to vanes with uniformly roughened surfaces. As a result, the corresponding normalized IAL value in Figure 19 is between values for the $k_{s} / c x=0.00108$ and $k_{s} / c x=0.00258$ uniformly roughened vanes for an exit Mach number of 0.71 [38].

6.6. Area-Averaged, Mass-Averaged Loss Coefficients. Different loss coefficient definitions are sometimes employed by different research groups. Of these, Boyle and Senyitko [64] and Boyle et al. [30] employ an area averaged loss coefficient, $Y_{A}$, in their analysis, as mentioned earlier. In their investigation, Boyle and Senyitko [64] employ vanes with $5.18 \mathrm{~cm}$ axial chord length and $75^{\circ}$ flow turning angle. Their data are based on measurements made 0.35 of an axial chord length downstream of their vane trailing edge. Boyle et al. [30] employ vanes with $4.445 \mathrm{~cm}$ axial chord length and approximately $80^{\circ}$ flow turning angle in their numerical prediction. Figure 20 shows comparisons of their 


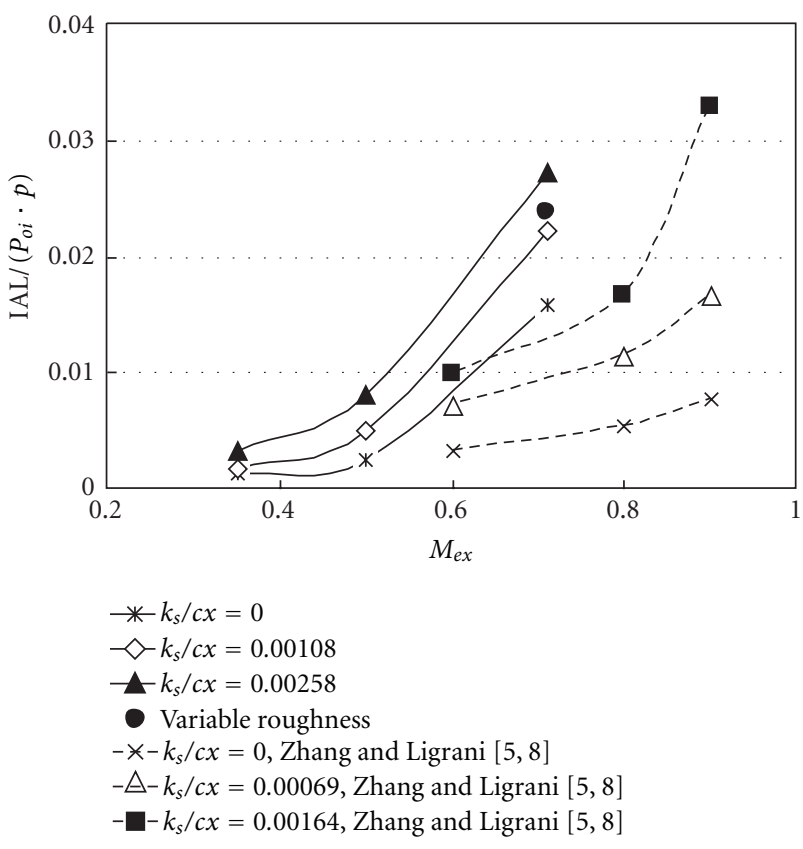

FIGURE 19: Comparison of normalized integrated aerodynamic loss magnitudes as dependent upon exit Mach number, and measured one chord length downstream of the cambered and symmetric airfoils, for $T u=1.1-1.6$ percent for a cambered vane [38].

data with results from the present study over a range of exit Mach numbers which are measured $0.25 c x$ downstream of the vane in Figure 12. These data indicate that higher $Y_{A}$ losses are generally observed as higher inlet turbulence intensity levels are present. Excellent agreement is shown in Figure 20 between results from Boyle and Senyitko [64] and the present study at low exit Mach number. For the present study, $M_{e x}=0.35$ and $\operatorname{Re}=0.5 \times 10^{6}$, whereas $M_{e x}=0.3$ and approximately $\mathrm{Re}=0.52 \times 10^{6}$ for Boyle and Senyitko [64]. Predicted values at high exit Mach numbers are lower than the present experimental results, but differences are relatively small, and the trends are generally consistent. Here, $M_{e x}=0.7$ and $\operatorname{Re}=1 \times 10^{6}$ for Boyle et al. [30], compared to $M_{e x}=0.71$ and $\operatorname{Re}=0.95 \times 10^{6}$ for the present study. Therefore, to some extent, the present experimental data validate the numerical code and procedures employed by Boyle et al. [30].

Figure 21 shows comparisons of the data of Boyle et al. [30] and Boyle and Senyitko [64] with results from Zhang et al. [38] over a range of exit Mach numbers and different $k_{s} / c x$ values. These data indicate that higher $Y_{A}$ losses are generally observed as either exit Mach number or surface roughness increases. Of particular interest is the dramatic increase in $Y_{A}$ magnitudes that occurs as the exit Mach number increases from 0.5 to 0.7 for the airfoils with $k_{s} / c x$ magnitudes of 0 and 0.0108. Note that $Y_{A}$ magnitudes from smooth vanes from Boyle and Senyitko [64] and Boyle et al. [30] are different from each other because of different vane configurations and different operating conditions in the two investigations. Such

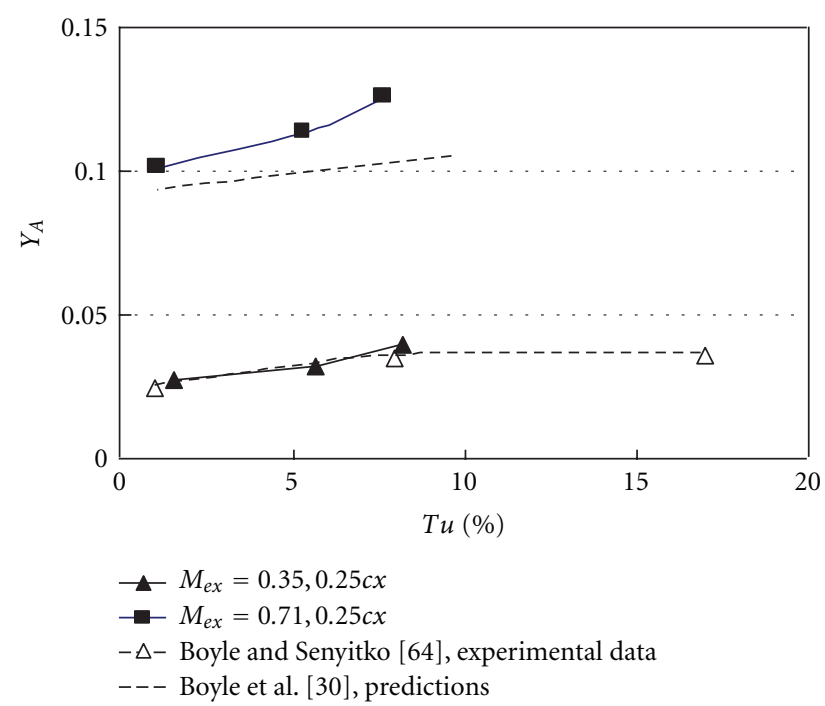

Figure 20: Comparison of area-averaged loss coefficients with values from Boyle and Senyitko [64], and Boyle et al. [30], for smooth, cambered vanes [37].

differences also partially account for some of the differences between these data and results from the present investigation.

Data from Kind et al. [22] are presented and compared with some data from Zhang et al. [38] in Figure 22. The Kind et al. data are measured 0.4 of an axial chord length downstream of their airfoil. In Figure 22, $Y_{P^{\prime}}$ loss coefficient data are given as they vary with normalized mean roughness height $k / c$ since sandgrain roughness height, $k_{s}$, is not available from Kind et al. [22]. $Y_{P^{\prime}}$ loss coefficient results from Zhang et al. as well as from Kind et al. [22] increase as the normalized mean roughness height becomes larger. Similar magnitudes of $Y_{P^{\prime}}$ for the two studies are evident for $k / c=0$ (i.e., smooth vane surfaces). However, differences are evident between the two data sets when $k / c>0$, which are most likely due to different surface roughness characteristics. For example, the Kind et al. [22] roughness with $k / c$ of 0.002 may be comprised of roughness elements with different density compared to ones employed in the present study. Such roughness could thus give different $Y_{P^{\prime}}$ loss coefficient magnitudes even though mean roughness heights may be comparable.

\section{Cambered Vanes with Film Cooling}

This investigation is focused on investigation of the effects of film cooling hole shape, orientation, blowing ratio, as well as the number of rows of holes, and their resulting effect on the aerodynamic losses. The film cooling holes are located on the suction side gill region of a simulated cambered turbine blade. Four different hole configurations are tested at two different blowing ratios, utilizing either a single or two rows of film cooling holes. Carbon dioxide is used as the injectant to achieve a density ratio of 1.9-2.0 similar to values present in operating gas turbine engines. A mesh grid is used to augment the magnitudes of longitudinal turbulence intensity 


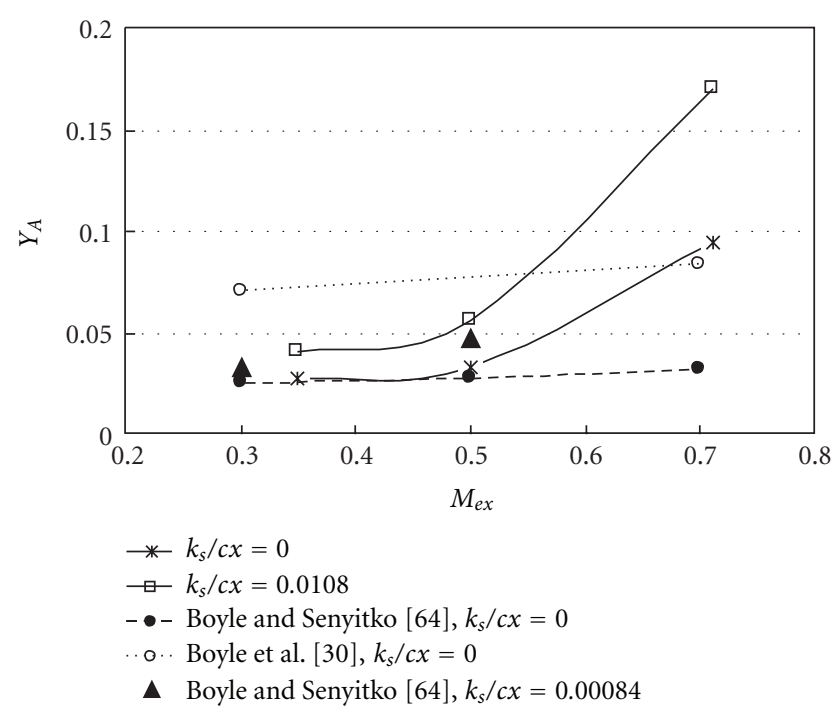

Figure 21: Comparison of area-averaged loss coefficient with Boyle and Senyitko [64], and Boyle et al. [30], for a cambered vane with $T u=1.1-1.6$ percent [38].

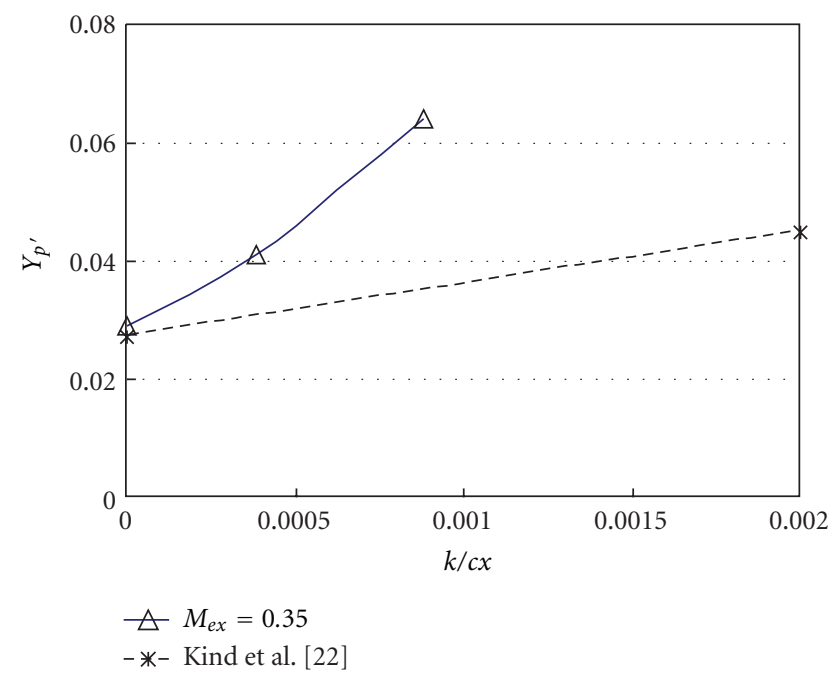

Figure 22: Comparison of mass-averaged loss coefficients with similar results from Kind et al. [22], for a cambered vane with $T u=$ $1.1-1.6$ percent [38].

at the inlet of the test section.

7.1. Test Section and Test Vane. The test section is designed to match Reynolds numbers, Mach numbers, pressure gradients, passage mass flow rates, boundary layer development, streamline curvature, airfoil camber, and physical dimensions of turbine vanes in operating aeroengines and in gas turbines used for utility power generation. A schematic diagram of the test section with the cambered vane is shown in Figure 12. The inlet of the test section is $12.70 \mathrm{~cm}$ by

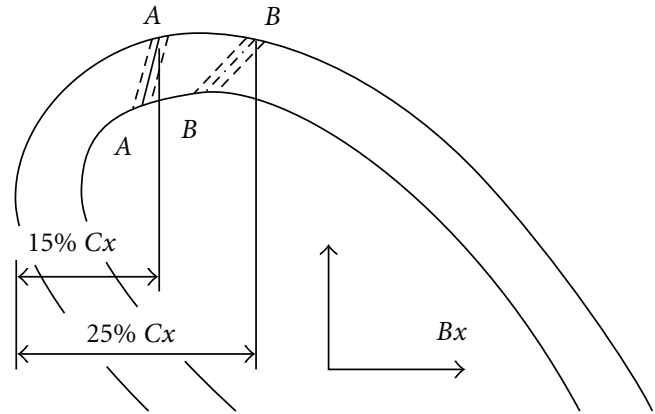

FIGURE 23: Film-cooling hole locations, for cambered vanes with film cooling [55].

$12.70 \mathrm{~cm}$. Appropriate cascade flow conditions are maintained by a pair of adjustable bleed ducts, and two exit tailboards, which are also shown in Figure 12. By adjusting these items, appropriate Mach number distributions along the test vane are obtained. Film cooling configurations and conditions and geometric parameters of the test vane are given by Chappell et al. [55].

7.2. Film Cooling Hole Configurations. Four different hole configurations are investigated: round axial (ra), shaped axial (sa), round radial (rr), and round compound (rc) [55]. For each configuration, either the first upstream row of holes only is employed, or two rows of holes are employed. The holes located in each row are staggered with respect to each other. As shown in Figure 23 the hole exits for all four arrangements are located at $15 \%$ and $25 \%$ of the axial chord. In addition, the holes in each row have the same spanwise hole diameter spacing of $6 \mathrm{~d}$. The row of holes marked a-a in Figure 23 contains 13 film cooling holes, and the row of holes marked by b-b in Figure 23 contains 14 film cooling holes. Note that the rr and rc configurations are unique because of the large compound angles which are employed [55]. The inclination and orientation angles of the different hole configurations are given in Table 4 . The shaped axial (sa) holes are both laterally diffused and forward diffused. Additional configuration and geometry details for all four hole arrangements are provided by chappell et al. [55].

7.3. Secondary Film Cooling Injection System. Carbon dioxide is used as the injectant to achieve density ratios similar to those experienced in operating gas turbine engines, $\rho_{c} / \rho_{\infty}=1.9-2.0$. With the present secondary injection system arrangement, regulated carbon dioxide leaves its tank and first goes through a sonic orifice, which is used in conjunction with pressure and temperature measurements to determine the injectant mass flow rate. After leaving the sonic orifice, the injectant enters a TV-050 heat exchanger, which uses liquid nitrogen as a coolant. As the injectant is cooled, it is passed through a by-pass valves until the mainstream air is started, to prevent any advance cooling of the vane. Just prior to the mainstream blowdown, valves are arranged so that the injectant flows through the vane and out of the film cooling holes. To approximate a plenum 
condition, the injectant enters the injectant passage from both spanwise sides of the vane [55].

\subsection{Test Section Flow Characteristics and Mach Number} Distributions. During each test, the inlet total pressure at the inlet of the test section (one axial chord length upstream of the vane leading edge) is maintained constant at $94 \mathrm{kPa}$. This corresponds to an exit freestream Mach number of 0.35 and an exit Reynolds number based on axial chord of $0.5 \times$ $10^{6}$, as measured 0.25 axial chord lengths downstream the airfoil trailing edge. The magnitudes of the inlet mainstream longitudinal turbulence intensity and length scale for the present experimental conditions are 5.7 percent and $2.2 \mathrm{~cm}$, respectively. Here, turbulence intensity is defined as the ratio of the root-mean square of the longitudinal fluctuation velocity component divided by the local streamwise mean component of velocity. Figure 13 shows the Mach number distributions along the turbine vane pressure side and along the vane suction side for the present operating conditions with $M_{e x}=0.35$. The data shown in this figure are based upon measurements of total pressure at the test section inlet, and vane mid-span static pressures. As shown in Figure 13, the Mach number distribution employed in this study is subsonic on the vane suction and pressure sides, with an adverse pressure gradient on the suction side of the vane when $B x / c x>0.60$. As such, the present Mach number distribution is in excellent agreement with data for gas turbine vanes from industry [55].

7.5. Integrated Aerodynamic Losses. Figures 24 and 25 present normalized integrated aerodynamic loss data, after subtracting off the IAL value for no-film cooling. These data are given as they depend upon blowing ratio and show important variations with film cooling hole configuration and arrangement. In Figure 25 (which presents both rows data), differences between the RR, RC, and SA sets of IAL data are quite small, with IAL values which are significantly higher than ones produced by the RA configuration (at particular blowing ratio values). In all cases, IAL values increase continuously with blowing ratio. IAL values in Figures 24 and 25 are compared with the one-dimensional mixing loss equation given by $(17)[54,55]$. Here, $C_{1}$ values are given in Table 3 for the different film cooling arrangements, and $M_{\infty}, \dot{m}_{\infty}$, and $u_{\infty}$ are freestream values at the streamwise locations of the film cooling holes. Equation (17) (with $C_{1}$ values from Table 3 ) shows good agreement with much of the data in Figures 24 and 25, including its dependence upon blowing ratio $m$ and number of rows of film cooling holes. In particular, the correlation equation matches most of the both rows data in Figure 25. In Figure 24 for the first row data, the RA, RC, and RR data sets are well aligned with correlation (17) [55].

The thermal performance characteristics of the RR, RA, RC, and SA holes are described by Chappell et al. [69]. Bunker [70, 71] provides information on the thermal performance characteristics of numerous other film cooling hole configurations.

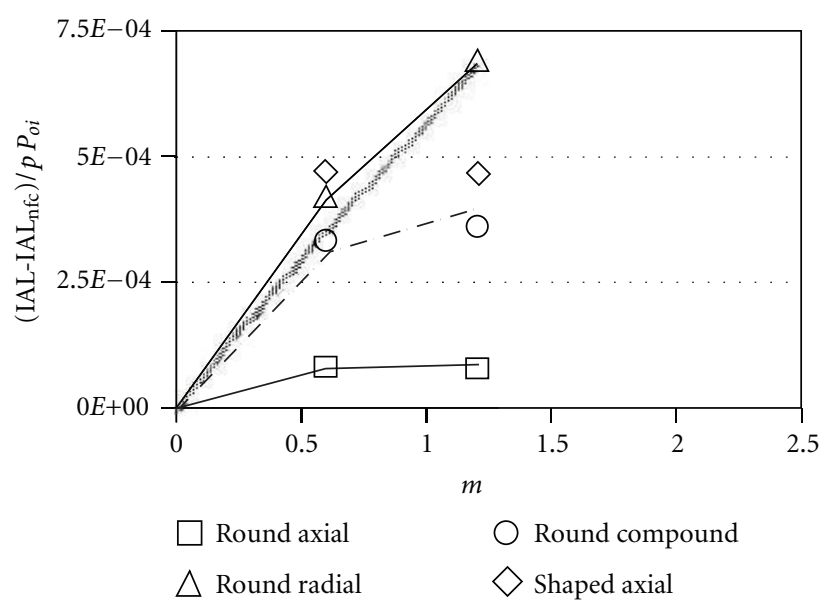

FIGURE 24: Normalized Integrated Aerodynamic Loss values for different hole configurations for film injection from the first row of holes only, for cambered vanes with film cooling [55]. Lines are determined using (17) and $C_{1}$ values from Table 3.

TABLe 3: $C_{1}$ values for (17) [55].

\begin{tabular}{lcc}
\hline Hole configuration & First row & Both rows \\
\hline Round axial & 0.29 & 0.70 \\
Round compound & 4.78 & 2.71 \\
Round radial & 3.93 & 2.70 \\
Shaped axial & 2.10 & 2.40 \\
\hline
\end{tabular}

\section{Second Law Loss Analyses}

Overall, mass-averaged magnitudes of exergy destruction are compared in Figure 26 for the cambered vane and the symmetric airfoil, as they vary with surface roughness. These data are given for different measurement locations downstream of different airfoils with different exit Mach numbers, for freestream turbulence intensity values from 0.9 to 1.5 percent. Dramatic increases of $x_{\text {dest }, o}$ are apparent as either $k_{s} / c$ or as $M_{e x}$ increases. Overall, the symmetric airfoil $x_{\text {dest,o }}$ results appear to be lower than the cambered airfoil results, when compared at the same $k_{s} / c, M_{e x}$, and $x / c x$. Similar conclusions are evidenced by the results which are presented in Figure 27, where overall exergy destruction values are given as they vary with freestream turbulence intensity. However, within this figure, increases of $x_{\text {dest }, o}$ with $T u$ are relatively small. Figure 28 shows how exergy destruction changes with different film cooling conditions and configurations. Here, magnitudes for the symmetric airfoil are significantly higher than values for the cambered airfoil, which is consistent with Integrated Aerodynamic Loss data.

\section{Summary and Conclusions}

Experimental and numerical results are presented from a series of investigations which have taken place over the past 32 years. Considered are effects of mainstream turbulence intensity, surface roughness, exit Mach number, and airfoil 
TABLE 4: Inclination and orientation angles for the RA, RC, RR, and SA film cooling hole configurations [55].

(a)

\begin{tabular}{|c|c|c|c|c|c|c|c|}
\hline \multicolumn{8}{|c|}{ Inclination angles } \\
\hline \multicolumn{2}{|c|}{ Round axial } & \multicolumn{2}{|c|}{ Round compound } & \multicolumn{2}{|c|}{ Round radial } & \multicolumn{2}{|c|}{ Shaped axial } \\
\hline First row & Second row & First row & Second row & First row & Second row & First row & Second row \\
\hline 65 & 60 & 18.06 & 17.22 & 20 & 20 & 55 & 50 \\
\hline \multicolumn{8}{|c|}{ Both row average inclination angle } \\
\hline \multicolumn{2}{|c|}{62.5} & \multicolumn{2}{|c|}{17.64} & \multicolumn{2}{|c|}{20} & \multicolumn{2}{|c|}{52.5} \\
\hline
\end{tabular}

(b)

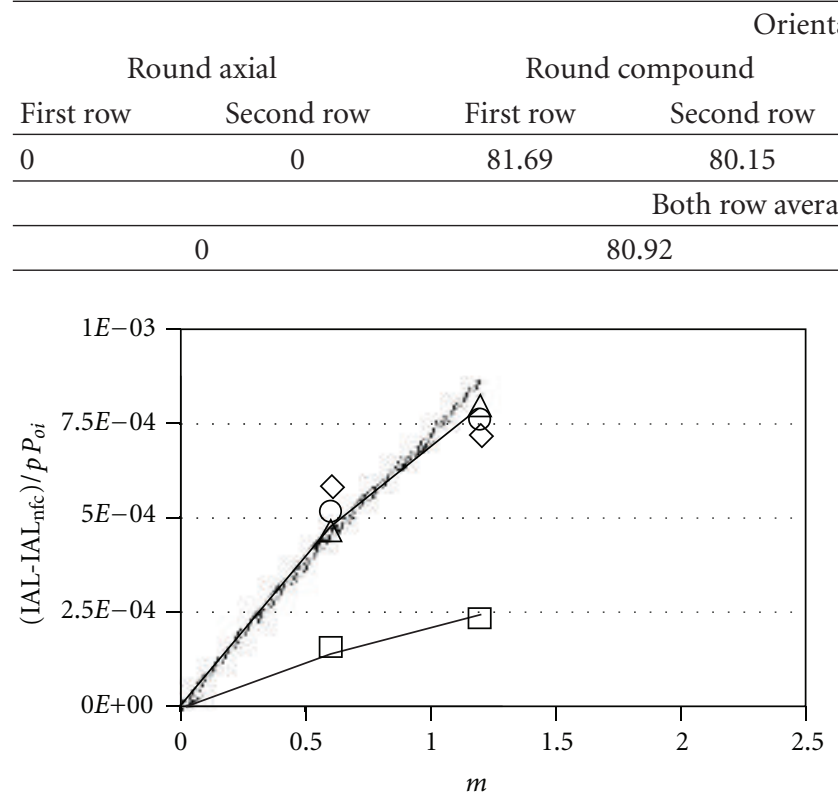

FIGURE 25: Normalized Integrated Aerodynamic Loss values for different hole configurations for film injection from both rows of holes, for cambered vanes with film cooling [55]. Symbols are defined in Figure 24. Lines are determined using (17) and $C_{1}$ values from Table 3 .

camber as they influence local and integrated parameters which quantify aerodynamic losses for symmetric airfoils and cambered vanes, both with and without film cooling. The turbine airfoils are investigated within compressible, high-speed flows with either subsonic or transonic Mach number distributions.

Local and global aerodynamic losses are also quantified using second law analyses. For each experimental arrangement, an overall, mass-averaged magnitude of exergy destruction is determined. Comparisons of these values for the different physical phenomena, which are investigated, provide quantitative assessments of the relative irreversibilities which result from the different phenomena which are considered. Relative to a smooth, symmetric airfoil with no film cooling at low Mach number and low freestream turbulence intensity overall, the largest increases in exergy destruction occur with increasing Mach number, and increasing surface roughness. Important variations are also observed as airfoil camber changes. Progressively smaller mass-averaged
Round radial Shaped axial

\begin{tabular}{cccc} 
First row & Second row & First row & Second row \\
90 & 90 & 0 & 0 \\
\hline 90 & & \\
\hline orientation angle & & 0 \\
\hline
\end{tabular}

\begin{tabular}{|cccc|}
\cline { 2 - 4 } \multicolumn{1}{c|}{} & $x / c x$ & $M_{e x}$ & Airfoil \\
\hline$\triangle$ & 0.25 & 0.71 & Cambered \\
$\triangle$ & 0.25 & 0.71 & Cambered (variable rough.) \\
$\bigcirc$ & 1 & 0.35 & Cambered \\
$\square$ & 1 & 0.5 & Cambered \\
$\diamond$ & 1 & 0.71 & Cambered \\
$\diamond$ & 1 & 0.71 & Cambered (variable rough.) \\
$\square$ & 1 & 0.9 & Symmetric \\
\hline
\end{tabular}

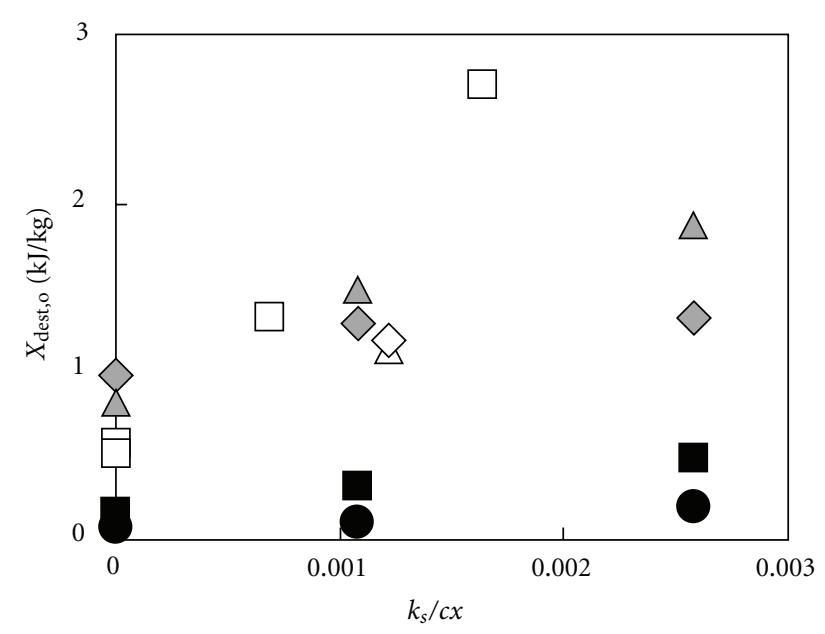

Figure 26: Overall exergy destruction as it varies with surface roughness condition for different measurement locations downstream of different airfoils with different exit Mach numbers, for freestream turbulence intensity values from 0.9 to 1.5 percent.

exergy destruction increases are then observed with changes of freestream turbulence intensity, and different film cooling conditions.

The effects of surface roughness on the aerodynamic performance of symmetric turbine airfoils (each with a Mach number variation from 0.4 to 0.7 ) are investigated with inlet turbulence intensity levels of 0.9 percent, 5.5 


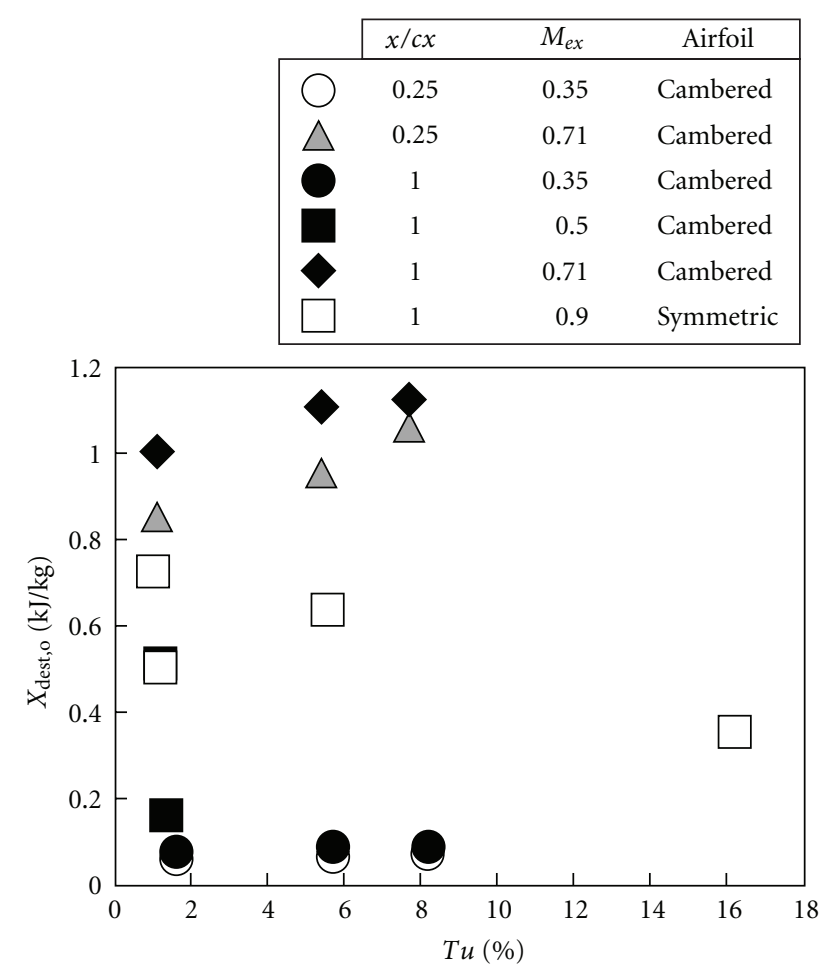

Figure 27: Overall exergy destruction as it varies with surface freestream turbulence intensity for different measurement locations downstream of different smooth airfoils with different exit Mach numbers.

percent, and 16.2 percent, and with ratios of equivalent sandgrain roughness size to airfoil chord length $k_{s} / c$ of 0 , 0.00069 , and 0.00164 . Results show that changing the airfoil surface roughness condition has a substantial effect on the normalized and dimensional magnitudes of Integrated Aerodynamic Losses produced by the airfoils. Relative to smooth airfoils, this is due to (i) augmentations of mixing and turbulent transport in the boundary layers which develop along the roughened airfoils, (ii) thicker boundary layers at the trailing edges of roughened airfoils, (iii) separation of flow streamlines at the airfoil trailing edges, and (iv) increased turbulent diffusion in the transverse direction within the wakes of roughened airfoils as they advect downstream. In contrast, Integrated Aerodynamic Losses show much weaker dependence upon inlet freestream turbulence intensity level. Also considered are the combined effects of surface roughness, exit freestream Mach number, and turbulence intensity on the aerodynamic performance of symmetric turbine airfoils. According to these results, the dependence of aerodynamic losses on mainstream turbulence intensity and freestream Mach number is vastly different as level of airfoil surface roughness changes. For example, magnitudes of Integrated Aerodynamic Losses change by much larger amount as either the freestream Mach number or turbulence intensity are altered, when the airfoil is roughened. This is partially a result of the thicker boundary layers which develop over the roughened surfaces giving greater blockage and less expansion of the flow through the airfoil passage.

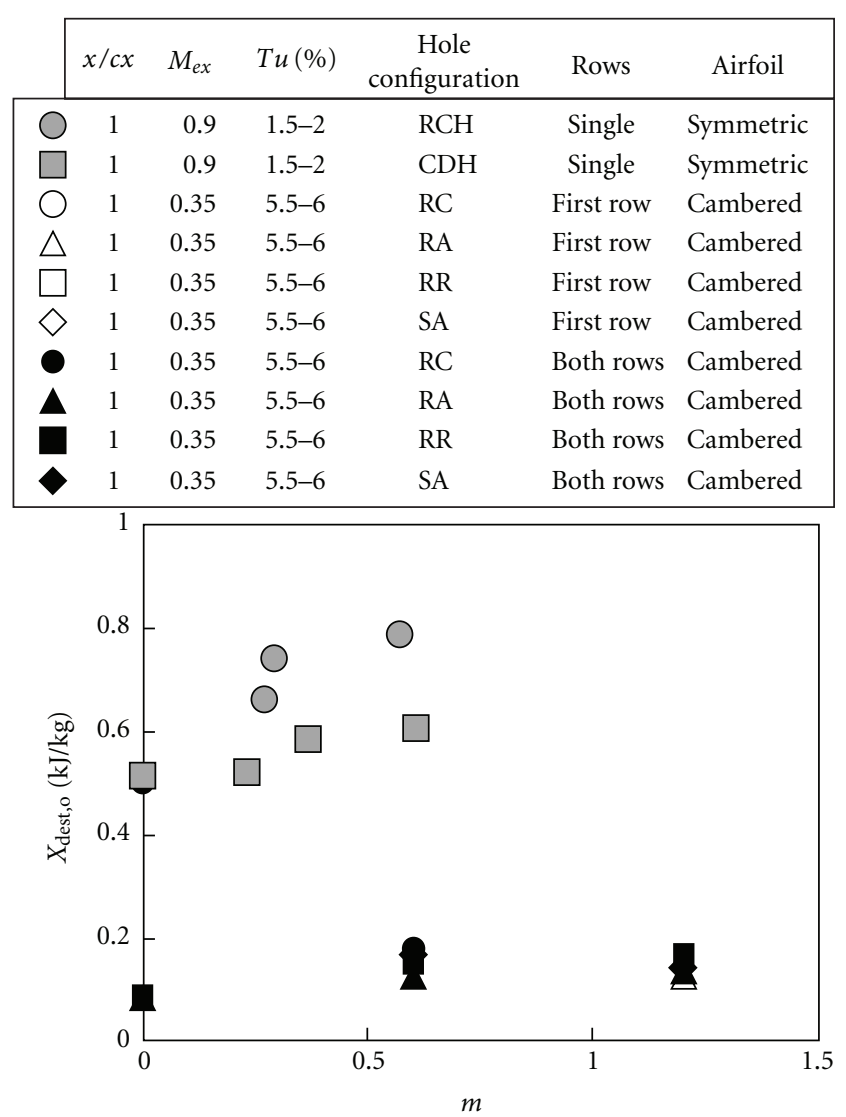

FIGURE 28: Overall exergy destruction as it varies with film cooling blowing ratio as measured one axial chord length downstream of different smooth airfoils with different exit Mach numbers, and different film cooling configurations and conditions.

With film cooling employed on the symmetric airfoils, two different film cooling hole configurations are located just downstream of the passage throat where the freestream Mach number is nominally 1.07 (i) simple angle, round cylindrical holes (RCH) and (ii) simple angle, conical diffused holes $(\mathrm{CDH})$. Local total pressure loss coefficient data show that the aerodynamic losses due to mixing are significantly greater than those due to oblique trailing edge shock waves. Contributions to total pressure coefficient profiles from the two types of losses are separated by assuming that shock losses are the same magnitude at all $y / c x$ throughout the wake and adjacent freestream flows. In some cases, the cooling films reduce the strength of the shock waves (and the associated aerodynamic losses) by greater amounts as the blowing ratio increases, particularly with higher density ratio films from the $\mathrm{CDH}$ configuration. Such decreases are evidenced by reduced freestream pressure coefficients which are accompanied by increased shock wave angles and smaller flow deflection angles.

Integrated aerodynamic mixing losses, measured one chord length downstream of the airfoil (and with the effects of the trailing edge oblique shock waves removed), are higher with film cooling than without. For each hole configuration investigated, integrated losses generally increase with injectant Mach number ratio as the film to freestream density ratio is approximately constant. Integrated aerodynamic 
losses are significantly lower with conical diffused holes than with cylindrical holes ( 3 times when compared at the same blowing ratio), which illustrates the strong dependence of aerodynamic mixing losses on film hole geometry. Such behavior is due to different amounts of mixing just downstream of the airfoils and different turbulent diffusion of streamwise momentum in a direction normal to the airfoil symmetry plane, both of which are evidenced by different aerodynamic loss profile magnitudes and levels of symmetry.

Downstream of cambered vanes with no film cooling, wake profiles of total pressure loss are asymmetric. This is due to different loading, different boundary layer growth, and different susceptibility to flow separation on the different vane surfaces, which also causes the suction side wakes (at negative $y / c x$ ) to be thicker than the pressure side wakes (at positive $y / c x)$. Overall, the wakes are pushed toward smaller $y / c x$ values as they are advected downstream (i.e., towards the vane suction side). The wake downstream of the vane becomes wider at higher exit Mach numbers as a result of higher advection speeds, as well as increased diffusion within the wake. Wake profiles also become broader with increased turbulence intensity levels, especially on the suction side. This partially due to the effects of suction side boundary layers, which are forced into transition farther upstream by the higher magnitudes of freestream turbulence. Increased diffusion from the wake to surrounding freestream flow also plays a role in producing such trends. In general, wake profiles are more sensitive to changes and augmentations of turbulence intensity at lower subsonic flow conditions than when transonic flow is present.

IAL magnitudes increase as higher Mach numbers are present along the cambered vanes. When compared at the same exit Mach number, the present normalized IAL data for cambered vanes are much higher than data obtained downstream of straight symmetric airfoils without flow turning. Overall, this means that greater losses are present with flow turning and cambered airfoils than with symmetric airfoils. Magnitudes of IAL also slightly increase as the inlet turbulence intensity level increases. The IAL differences obtained for each vane Mach number distribution for the $1 c x$ and $0.25 c x$ downstream measurement locations are relatively small compared to overall IAL loss magnitudes. This is because not much mean streamwise momentum is converted into turbulence by local shear and turbulence production as the wake is advected in the streamwise direction.

Magnitudes of area-averaged loss coefficients $Y_{A}$ also generally increase as exit Mach number increases. Excellent agreement is present between results from Boyle and Senyitko [59] and the present study for a low subsonic Mach number distribution along the vane, which gives an exit Mach number $M_{e x}$ of 0.35 . Other experimental data from the present investigation show similar qualitative trends and validate the numerical predictions by Boyle et al. [30] for a similar vane configuration when the Mach number distribution along the vane is transonic and $M_{e x}=0.71$.

When suction-side gill region film cooling is added to the cambered vanes, effects of film cooling hole orientation, shape, and number of rows are considered for four different hole configurations: round axial (RA), shaped axial (SA), round radial (RR), and round compound (RC). Results show that magnitudes of Integrated Aerodynamic Loss (IAL) increase anywhere from 4 to 45 percent compared to a smooth blade with no film injection [55]. The performance of each hole type depends upon the airfoil configuration, film cooling configuration, mainstream flow Mach number, number of rows of holes, density ratio, and blowing ratio, but the general trend is an increase in IAL as either the blowing ratio or the number of rows of holes increase. When both rows of holes IAL data are considered, differences between the RR, RC, and SA sets are quite small, with IAL values which are significantly higher than ones produced by the RA configuration (at a particular blowing ratio).

These integrated aerodynamic loss data for the cambered vane with film cooling are also compared with data from Jackson et al. [54], which are measured downstream of a symmetric airfoil with a single row of conical diffused holes located on one side. In general, the Jackson data are significantly higher than the cambered vane results, when compared at a particular film cooling blowing ratio. This is mostly a consequence of the transonic flow conditions and the symmetric airfoil arrangement with suction surface contours and high Mach number distributions on both sides for the Jackson et al. [54] airfoil.

\section{Nomenclature}

$B: \quad$ Parameter in equations (17) and (18)

$B x$ : Vane axial chord coordinate

$c x$ : Axial chord length of airfoil

$C x$ : Vane axial chord length

$C_{1}$ : Correlation constant

$C_{p}$ : Local total pressure loss coefficient, $\left(P_{o i}-P_{o e}\right) / P_{o i}$

$C_{p, \infty}$ : Total pressure loss coefficient in the freestream, $\left(P_{o i}-P_{o e, \infty}\right) / P_{o i}$

$h$ : Enthalpy

IAL: Integrated aerodynamic loss

$k$ : $\quad$ Ratio of specific heats

$k$ : Mean roughness height

$k_{s}$ : Equivalent sand grain roughness

KE: Normalized local kinetic energy, $\left(P_{o e}-P_{s e}\right) /\left(P_{o e}-P_{s e}\right)_{\infty}$

$M: \quad$ Local Mach number

$m$ : Blowing ratio for film cooling

$\dot{m}$ : Mass flow rate

$p: \quad$ Airfoil passage effective pitch

P: $\quad$ Pressure

PS: Pressure side

q: Dynamic pressure

$R: \quad$ Gas constant

$s: \quad$ Local entropy

SS: Suction side

$s_{\text {gen }}$ : Local entropy creation or local exergy destruction

T: Temperature

$T_{0}$ : Ambient temperature

Tu: Test section inlet longitudinal turbulence intensity level 


\author{
$u$ : Local streamwise velocity \\ $W$ : Local relative velocity \\ $x$ : Linear distance downstream of the vane or \\ airfoil measured from the vane or airfoil \\ trailing edge \\ $X: \quad$ Film cooling hole streamwise coordinate \\ $X: \quad$ Streamwise coordinate \\ $x_{\text {dest }, o}$ : Overall, mass-averaged exergy destruction \\ $y$ : Normal coordinate measured from vane \\ centerline \\ $Y$ : Normal coordinate \\ $Y_{A}$ : Area-averaged total pressure loss coeffi- \\ cient \\ $Y_{P}: \quad$ Total pressure loss coefficient \\ $Y_{P^{\prime}}$ : Mass-averaged total pressure loss coeffi- \\ cient \\ $Y_{S}: \quad$ Entropy rise coefficient \\ $Z$ : $\quad$ Film cooling hole spanwise coordinate.
}

\section{Greek Symbols}

$\theta$ : Film cooling holes inclination angle

$\rho:$ Local static density

$\Lambda_{s}$ : Roughness parameter

$\Omega$ : Total pressure loss coefficient

$\xi$ : Enthalpy loss coefficient or primary loss coefficient

$\xi_{\text {th }}:$ Thermodynamic loss coefficient.

\section{Subscripts}

A: Area-averaged value

c: Injectant or film coolant value at exit planes of film cooling holes

$\infty$ : Local freestream value

$i$ : Inlet of test section

$e: \quad$ Exit of test section

$m$ : Mass-averaged value

NFC: no film cooling value

$o$ : Total or stagnation value

ideal: Ideal isentropic value

$s: \quad$ Static value.

ex: $\quad$ Exit of test section, mainstream.

\section{Acknowledgments}

The author has been involved in investigations of turbine component aerodynamic losses over the past 14 years. Over this time period, many talented and dedicated individuals contributed to the research results which are presented within this paper. A partial list includes Prof. Qiang Zhang, Prof. Li He, Prof. Sang Woo Lee, Dr. Jae Sik Jin, Dr. P. D. Johnson, Dr. M. Goodro, Dr. D. O’Dowd, Dr. S. Sreekanth, Dr. T. Lucas, Dr. E. Vlasic, Mr. D. J. Jackson, Mr. K. L. Lee, Mr. J. C. Chappell, Mr. D. Sandberg, Mr. T. Furukawa, and Ms. I. Usandizaga.

\section{References}

[1] H. Hoheisel, R. Kiock, H. J. Lichtfuss, and L. Fottner, "Influence of free-stream turbulence and blade pressure gradient on boundary layer and loss behavior of turbine cascades," Journal of Turbomachinery, vol. 109, no. 2, pp. 210-219, 1987.

[2] D. G. Gregory-Smith and J. G. E. Cleak, "Secondary flow measurements in a turbine cascade with high inlet turbulence," Journal of Turbomachinery, vol. 114, no. 1, pp. 173-183, 1992.

[3] F. E. Ames and M. W. Plesniak, "The influence of largescale, high-intensity turbulence on vane aerodynamic losses, wake growth, and the exit turbulence parameters," Journal of Turbomachinery, vol. 119, no. 2, pp. 182-192, 1997.

[4] J. Moore, D. M. Shaffer, and J. G. Moore, "Reynolds stresses and dissipation mechanisms downstream of a turbine cascade," Journal of Turbomachinery, vol. 109, no. 2, pp. 258-267, 1987.

[5] Q. Zhang, S. W. Lee, and P. M. Ligrani, "Effects of surface roughness and turbulence intensity on the aerodynamic losses produced by the suction surface of a simulated turbine airfoil," Journal of Fluids Engineering, vol. 126, no. 2, pp. 257-265, 2004.

[6] Q. Zhang, S. W. Lee, and P. M. Ligrani, "Effects of surface roughness and freestream turbulence on the wake turbulence structure of a symmetric airfoil," Physics of Fluids, vol. 16, no. 6, pp. 2044-2053, 2004.

[7] Q. Zhang, P. M. Ligrani, and S. W. Lee, "Determination of rough-surface skin friction coefficients from wake profile measurements," Experiments in Fluids, vol. 35, no. 6, pp. 627635,2003

[8] Q. Zhang and P. M. Ligrani, "Mach number/surface roughness effects on symmetric transonic turbine airfoil aerodynamic losses," Journal of Propulsion and Power, vol. 20, no. 6, pp. 1117-1125, 2004.

[9] L. Xu and J. D. Denton, "The base pressure and loss of a family of four turbine blades," Journal of Turbomachinery, vol. 110, no. 1, pp. 9-17, 1988.

[10] D. J. Mee, N. C. Baines, M. L. G. Oldfield, and T. F. Dickens, "Examination of the contributions to loss on a transonic turbine blade in cascade," Journal of Turbomachinery, vol. 114, no. 1, pp. 155-162, 1992.

[11] M. S. Izsak and H.-W. D. Chiang, "Turbine and compressor wake modeling for blade forced response," ASME Paper 93GT-238, International Gas Turbine and Aeroengine Congress \& Exposition, Cincinnati, Ohio, USA, 1993.

[12] V. Michelassi, W. Rodi, and P.-A. Giess, "Experimental and numerical investigation of boundary-layer and wake development in a transonic turbine cascade," ASME Paper 97-GT483, International Gas Turbine and Aeroengine Congress \& Exposition, Orlando, Fla, USA, 1997.

[13] C. R. Joe, X. A. Montesdeoca, F. O. Soechting, C. D. MacArthur, and M. Meininger, "High pressure turbine vane annular cascade heat flux and aerodynamic measurements with comparisons to predictions," ASME Paper 98-GT-430, International Gas Turbine and Aeroengine Congress \& Exposition, Stockholm, Sweden, 1998.

[14] D. E. Bohn, V. J. Becker, K. D. Behnke, and B. F. Bonhoff, "Experimental and numerical investigations of the aerodynamical effects of coolant injection through the trailing edge of a guide vane," ASME Paper 97-GT-23, International Gas Turbine and Aeroengine Congress \& Exposition, Orlando, Fla, USA, 1997.

[15] J. Nikuradse, "Laws of flow in rough pipes," NACA TM 1292, National Advisory Committee on Aeronautics, 1933. 
[16] H. Schlichting, "Experimental investigation of the problem of surface roughness," NACA TM 832, National Advisory Committee on Aeronautics, 1936.

[17] A. Sigal and J. E. Danberg, "New correlation of roughness density effect on the turbulent boundary layer," AIAA Journal, vol. 28, no. 3, pp. 554-556, 1990.

[18] A. Sigal and J. E. Danberg, "Analysis of turbulent boundary layer over roughness surface with application to projectile aerodynamics," Tech. Rep. BRL-TR-2977, Army Ballistic Research Lab, Aberdeen Proving Grounds, Md, USA, 1988.

[19] J. A. Van Rij, B. J. Belnap, and P. M. Ligrani, "Analysis and experiments on three-dimensional, irregular surface roughness," Journal of Fluids Engineering, vol. 124, no. 3, pp. 671677, 2002.

[20] K. Bammert and H. Sandstede, "Influence of manufacturing tolerances and surface roughness of blades on the performance of turbines," ASME Paper 75-GT-35, International Gas Turbine and Aeroengine Congress \& Exposition, Houston, Tex, USA, 1975.

[21] K. Bammert and H. Sandstede, "Measurements of the boundary layer development along a turbine blade with rough surfaces," Journal of Engineering for Gas Turbines and Power, vol. 102, no. 4, pp. 978-983, 1980.

[22] R. J. Kind, P. J. Serjak, and M. W. P. Abbott, "Measurements and prediction of the effects of surface roughness on profile losses and deviation in a turbine cascade," ASME Paper 96GT-203, International Gas Turbine and Aeroengine Congress \& Exposition, Birmingham, UK, 1996.

[23] D. G. Bogard, D. L. Schmidt, and M. Tabbita, "Characterization and laboratory simulation of turbine airfoil surface roughness and associated heat transfer," Journal of Turbomachinery, vol. 120, no. 2, pp. 337-342, 1998.

[24] N. Abuaf, R. S. Bunker, and C. P. Lee, "Effects of surface roughness on heat transfer and aerodynamic performance of turbine airfoils," Journal of Turbomachinery, vol. 120, no. 3, pp. 522-529, 1998.

[25] R. Leipold, M. Boese, and L. Fottner, "The influence of technical surface roughness caused by precision forging on the flow around a highly loaded compressor cascade," Journal of Turbomachinery, vol. 122, no. 3, pp. 416-425, 2000.

[26] S. M. Guo, M. L. G. Oldfield, and A. J. Rawlinson, "Influence of discrete pin shaped surface roughness (p-pins) on heat transfer and aerodynamics of film cooled aerofoil," ASME Paper GT-2002-30179, International Gas Turbine and Aeroengine Congress \& Exposition, Amsterdam, The Netherlands, 2002.

[27] Q. Zhang and P. M. Ligrani, "Aerodynamic losses of a cambered turbine vane: influences of surface roughness and freestream turbulence intensity," Journal of Turbomachinery, vol. 128, no. 3, pp. 536-546, 2006.

[28] A. Hoffs, U. Drost, and A. Bölcs, "Heat transfer measurements on a turbine airfoil at various Reynolds numbers and turbulence intensities including effects of surface roughness," ASME Paper 96-GT-169, International Gas Turbine and Aeroengine Congress \& Exposition, Birmingham, UK, 1996.

[29] P. W. Giel, R. S. Bunker, G. J. Van Fossen, and R. J. Boyle, "Heat transfer measurements and predictions on a power generation gas turbine blade," ASME Paper 2000-GT-209, International Gas Turbine and Aeroengine Congress \& Exposition, Munich, Germany, 2000.

[30] R. J. Boyle, B. L. Luci, V. G. Verhoff, W. P. Camperchioli, and $\mathrm{H}$. La, "Aerodynamics of a transitioning turbine stator over a range of Reynolds numbers," ASME Paper 98-GT285, International Gas Turbine and Aeroengine Congress \& Exposition, Stockhom, Swenden, 1998.
[31] A. C. Nix, A. C. Smith, T. E. Diller, W. F. Ng, and K. A. Thole, "High intensity, large length-scale freestream turbulence generation in a transonic turbine cascade," ASME Paper GT-200230523, International Gas Turbine and Aeroengine Congress \& Exposition, Amsterdam, The Netherlands, 2002.

[32] D. B. M. Jouini, S. A. Sjolander, and S. H. Moustapha, "Aerodynamic performance of a transonic turbine cascade at off-design conditions," Journal of Turbomachinery, vol. 123, no. 3, pp. 510-518, 2001.

[33] R. W. Radomsky and K. A. Thole, "Detailed boundary layer measurements on a turbine stator vane at elevated freestream turbulence levels," Journal of Turbomachinery, vol. 124, no. 1, pp. 107-118, 2002.

[34] T. Arts, "Aerodynamic and thermal performance of a threedimensional annular transonic nozzle guide vane-part I, experimental investigation," in Proceedings of the 30th AIAA/ASME/SAE/ASEE Joint Propulsion Conference, AIAA paper 94-2929, Indianapolis, Ind, USA, 1994.

[35] T. Coton, T. Arts, and M. Lefèbvre, "Effects of Reynolds and Mach numbers on the profile losses of a conventional lowpressure turbine rotor cascade with an increasing pitch-chord ratio," Proceedings of the Institution of Mechanical Engineers Part A, vol. 215, no. 6, pp. 763-772, 2001.

[36] R. J. Boyle, B. L. Lucci, and R. G. Senyitko, "Aerodynamics performance and turbulence measurements in a turbine vane cascade," ASME Paper GT-2002-30434, International Gas Turbine and Aeroengine Congress \& Exposition, Amsterdam, The Netherlands, 2002.

[37] Q. Zhang, D. Sandberg, and P. M. Ligrani, "Influence of Mach number and freestream turbulence intensity on the aerodynamic losses of a turbine vane," Journal of Propulsion and Power, vol. 21, no. 6, pp. 988-996, 2005.

[38] Q. Zhang, M. Goodro, P. M. Ligrani, R. Trindade, and S. Sreekanth, "Influence of surface roughness on the aerodynamic losses of a turbine vane," Journal of Fluids Engineering, vol. 128 , no. 3, pp. 568-578, 2006.

[39] Q. Zhang and P. M. Ligrani, "Numerical predictions of Stanton numbers, skin friction coefficients, aerodynamic losses, and Reynolds analogy behavior for a transsonic turbine vane," Numerical Heat Transfer Part A, vol. 49, no. 3, pp. 237256, 2006.

[40] Q. Zhang and P. M. Ligrani, "Wake turbulence structure downstream of a cambered airfoil in transonic flow: effects of surface roughness and freestream turbulence intensity," International Journal of Rotating Machinery, vol. 2006, Article ID 60234, 12 pages, 2006.

[41] J. D. Denton, "Loss mechanisms in turbomachines," Journal of Turbomachinery, vol. 115, no. 4, pp. 621-656, 1993.

[42] S. Ito, E. R. G. Eckert, and R. J. Goldstein, "Aerodynamic loss in a gas turbine stage with film cooling," Journal of Engineering for Gas Turbiens and Power, vol. 102, no. 4, pp. 964-970, 1980.

[43] B. R. Haller and J. J. Camus, "Aerodynamic loss penalty produced by film cooling transonic turbine blades," Journal of Engineering for Gas Turbines and Power, vol. 106, no. 1, pp. 198-205, 1984.

[44] O. Kollen and W. Koschel, "Effect of film-cooling on the aerodynamic performance of a turbine cascade," AGARD CP 390, 1985.

[45] C. R. B. Day, M. L. G. Oldfield, and G. D. Lock, "Aerodynamic performance of an annular cascade of film cooled nozzle guide vanes under engine representative conditions," Experiments in Fluids, vol. 29, no. 2, pp. 117-129, 2000.

[46] Y. Hong, C. Fu, G. Cunzhong, and W. Zhongqi, "Investigation of cooling-air injection on the flow field within a linear turbine 
cascade," ASME Paper 97-GT-520, International Gas Turbine and Aeroengine Congress \& Exposition, Orlando, Fla, USA, 1997.

[47] C. Kapteijn, J. Amecke, and V. Michelassi, “Aerodynamic performance of a transonic turbine guide vane with trailing edge coolant ejection—part I—experimental approach," Journal of Turbomachinery, vol. 118, no. 3, pp. 519-528, 1996.

[48] E. P. Vlasic, S. Girgis, and S. H. Moustapha, "The design and performance of a high work research turbine," Journal of Turbomachinery, vol. 118, no. 4, pp. 792-799, 1996.

[49] C. H. Sieverding, T. Arts, R. Dénos, and F. Martelli, "Investigation of the flow field downstream of a turbine trailing edge cooled nozzle guide vane," Journal of Turbomachinery, vol. 118, no. 2, pp. 291-300, 1996.

[50] T. Tanuma, N. Shibukawa, and S. Yamamoto, "Navier-Stokes analysis of unsteady transonic flows through gas turbine cascades with and without coolant ejection," ASME Paper 97GT-479, International Gas Turbine and Aeroengine Congress \& Exposition, Orlando, Fla, USA, 1997.

[51] C. Osnaghi, A. Perdichizzi, M. Savini, P. Harasgama, and E. Lutum, "The influence of film-cooling on the aerodynamic of a turbine nozzle guide vane," ASME Paper 97-GT-522, International Gas Turbine and Aeroengine Congress \& Exposition, Orlando, Fla, USA, 1997.

[52] R. Kubo, F. Otomo, Y. Fukuyama, and T. Nakata, "Aerodynamic loss increase due to individual film cooling injections from gas turbine nozzle surface," ASME Paper 98-GT-497, International Gas Turbine and Aeroengine Congress \& Exposition, Stockholm, Sweden, 1998.

[53] M. F. Urban, J. Hermeler, and H.-G. Hosenfeld, "Experimental and numerical investigations of film-cooling effects on the aerodynamic performance of transonic turbine blades," ASME Paper 98-GT-546, International Gas Turbine and Aeroengine Congress \& Exposition, Stockholm, Sweden, 1998.

[54] D. J. Jackson, K. L. Lee, P. M. Ligrani, and P. D. Johnson, "Transonic aerodynamic losses due to turbine airfoil, suction surface film cooling," Journal of Turbomachinery, vol. 122, no. 2, pp. 317-326, 2000.

[55] J. C. Chappell, P. M. Ligrani, S. Sreekanth, T. Lucas, and E. Vlasic, "Aerodynamic performance of suction-side gill region film cooling," Journal of Turbomachinery, vol. 132, no. 3, pp. 031020-1-031020-11, 2010.

[56] M. Raffel and F. Kost, "Investigation of aerodynamic effects of coolant ejection at the trailing edge of a turbine blade model by PIV and pressure measurements," Experiments in Fluids, vol. 24, no. 5-6, pp. 447-461, 1998.

[57] F. Kost and A. T. Holmes, "Aerodynamic effect of coolant ejection in the rear part of transonic rotor blades," AGARD CP 390, pp. 41-1-41-11, 1985.

[58] U. Drost and A. Bölcs, "Performance of a turbine airfoil with multiple film cooling stations, part ii: aerodynamic losses," ASME Paper 99-GT-42, International Gas Turbine and Aeroengine Congress \& Exposition, Indianapolis, Ind, USA, 1999.

[59] F. E. Ames, J. D. Johnson, and N. J. Fiala, "The influence of aero-derivative combustor turbulence and Reynolds number on vane aerodynamics losses, secondary flows, and wake growth," ASME Paper GT2006-90168, International Gas Turbine and Aeroengine Congress \& Exposition, Barcelona, Spain, 2006.

[60] I. Jaswal, E. L. Erickson, and F. E. Ames, "Aerodynamics of a covered trailing edge vane-effects of blowing rate, Reynolds number, and external turbulence," ASME Paper GT200959836, International Gas Turbine and Aeroengine Congress \& Exposition, Orlando, Fla, USA, 2009.

[61] J. D. Johnson, N. J. Fiala, and F. E. Ames, "Gill slot trailing edge aerodynamics: effects of blowing rate, Reynolds number, and external turbulence on Aerodynamic losses and pressure distribution," Journal of Turbomachinery, vol. 131, no. 1, pp. 011016-1-011016-11, 2009.

[62] E. L. Erickson, F. E. Ames, and J. P. Bons, "Effects of a realistically rough surface on vane aerodynamic losses including the influence of turbulence condition and Reynolds number," ASME Paper GT2010-22173, International Gas Turbine and Aeroengine Congress \& Exposition, Glasgow. Scotland, 2010.

[63] N. J. Fiala, J. D. Johnson, and F. E. Ames, "Aerodynamics of a letterbox trailing edge: effects of blowing rate, Reynolds number, and external turbulence on aerodynamic losses and pressure distribution," Journal of Turbomachinery, vol. 132, no. 4, pp. 041011-1-041011-11, 2010.

[64] R. J. Boyle and R. G. Senyitko, "Measurements and predictions of surface roughness effects on turbine vane aerodynamics," ASME Paper GT-2003-38580, International Gas Turbine and Aeroengine Congress \& Exposition, Atlanta, Ga, USA, 2003.

[65] S. Friedrichs, H. P. Hodson, and W. N. Dawes, "Aerodynamic aspects of endwall film-cooling," ASME Paper 96-GT-208, International Gas Turbine and Aeroengine Congress \& Exposition, Birmingham, UK, 1996.

[66] Y. A. Çengel and M. A. Boles, Thermodynamics An Engineering Approach, McGraw-Hill, New York, NY, USA, 7th edition, 2011.

[67] T. Furukawa and P. M. Ligrani, "Transonic film cooling effectiveness from shaped holes on a simulated turbine airfoil," Journal of Thermophysics and Heat Transfer, vol. 16, no. 2, pp. 228-237, 2002.

[68] J. D. Anderson, Modern Compressible Flow, McGraw-Hill, New York, NY, USA, 1990.

[69] J. C. Chappell, P. M. Ligrani, S. Sreekanth, and T. Lucas, "Suction-side gill region film cooling: effects of hole shape and orientation on adiabatic effectiveness and heat transfer coefficient," Journal of Turbomachinery, vol. 132, no. 3, pp. 031022-1-031022-11, 2010.

[70] R. S. Bunker, "Gas turbine heat transfer: 10 remaining hot gas path challenges," ASME Paper GT2006-90002, International Gas Turbine and Aeroengine Congress \& Exposition, Barcelona, Spain, 2006.

[71] R. S. Bunker, "Film cooling: breaking the limits of diffusion shaped holes," Heat Transfer Research, vol. 41, no. 6, pp. 627650, 2010. 

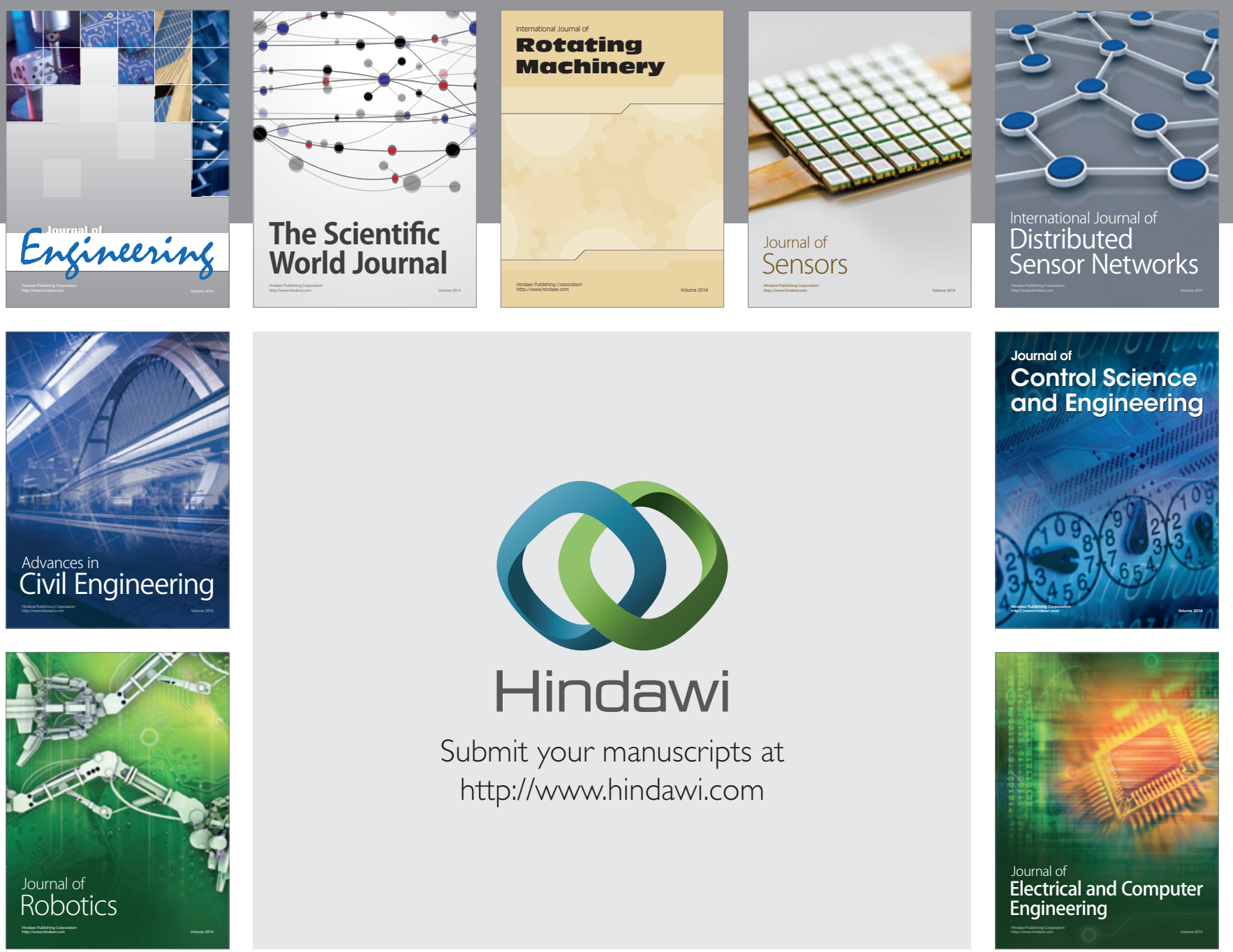

Submit your manuscripts at

http://www.hindawi.com
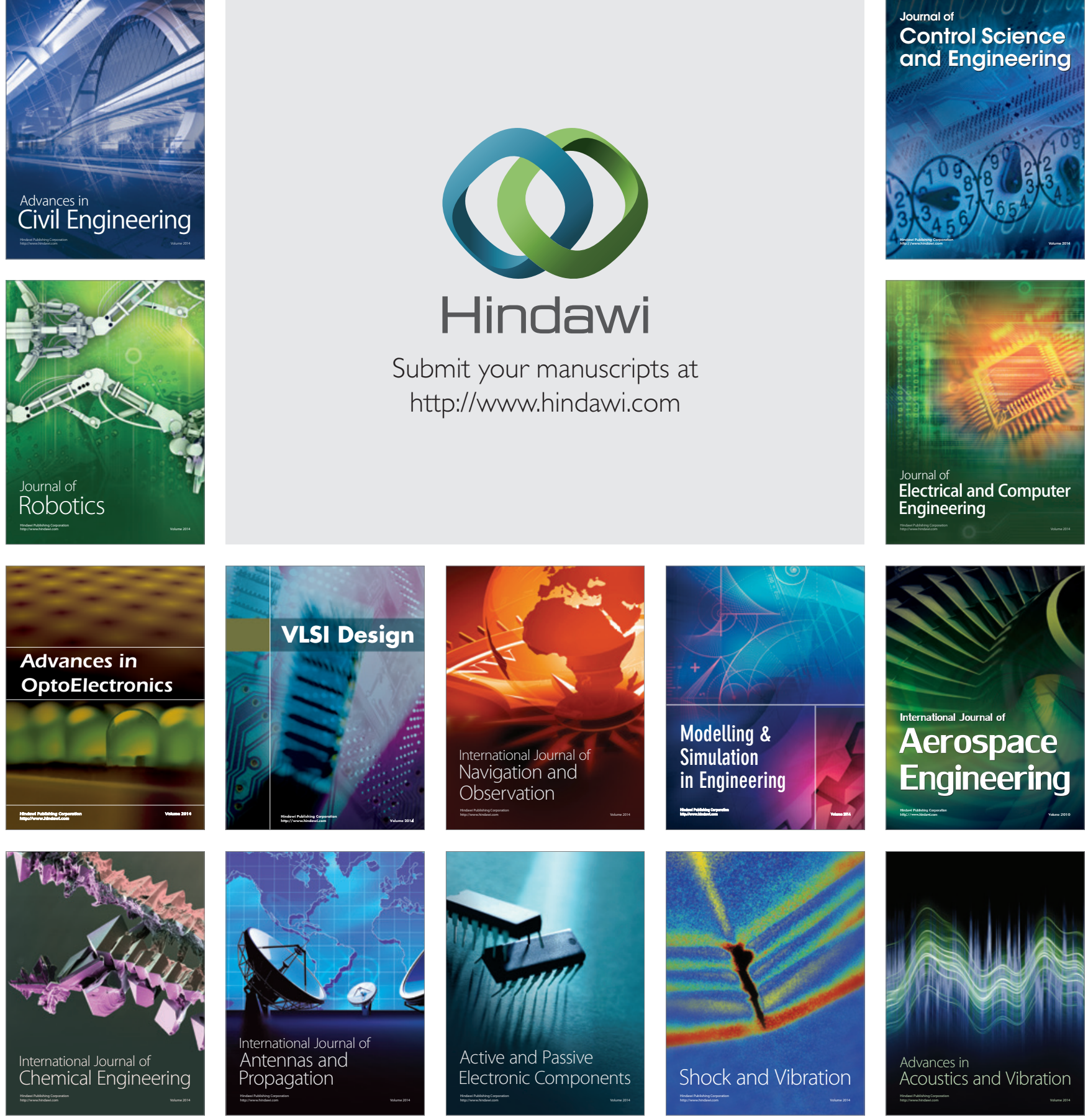